\title{
perspectivas MEDICINA LEGAL E PERICIAS MEDICAS
}

v.5 n.1 2020 


\title{
perspectivas \\ MEDICINA LEGALE \\ PERÍCIAS MÉDICAS
}

\author{
EDITOR CHEFE
}

Prof. Dr. Jose Jozefran Berto Freire (Associação Brasileira de Medicina Legal e Perícias Médicas (ABMLPM), São Paulo, SP Brasil)

\section{EDITORA EXECUTIVA}

Liege Gonzalez Jung (Indexa Editora, Rio de Janeiro, RJ Brasil)

\section{COMISSÃO EDITORIAL}

Prof. Dr. Aurélio Luna Maldonado (Universidad de Murcia, Murcia, Espanha)

Prof. Dr. Daniel Romero Muñoz (Faculdade de Ciências Médicas da Santa Casa, São Paulo, SP Brasil)

Prof. Dr. Duarte Nuno Pessoa Vieira (Universidade de Coimbra, Coimbra, Portugal)

Prof. Dr. Fernando Verdu Pascual (Universidad de Valencia, Valencia, Espanha)

Prof. Dr. Francisco Corte Real Gonçalves (Instituto Nacional de Medicina Legal, Lisboa, Portugal)

Prof. Dr. Genival Veloso de França (Universidade Federal da Paraíba, João Pessoa, PB Brasil)

Prof. Dr. Hugo Rodriguez Almada (Universidad de la Republica, Montevidéu, Uruguai)

Prof. Dr. Hygino de Carvalho Hércules (Unievangélica, Anápolis, GO Brasil)

Prof. Dr. Ivan Dieb Miziara (Universidade de São Paulo, São Paulo, SP Brasil)

Prof. Ms. Jarbas Simas (INSS, São Paulo, SP Brasil)

Dr. Jonas Borracini (Instituto de Medicina Social de São Paulo IMESC, São Paulo, SP Brasil)

Prof. Dr. Jorge Bermudez (Faculdad de Medicina de Buenos Aires, Buenos Aires, Argentina)

Prof. Dr. Lucas Pedroso Fernandes Ferreira Leal (Instituto de Medicina Social de São Paulo IMESC, São Paulo, SP Brasil)

Prof. Dr. Luiz Airton Saavedra de Paiva (Polícia Civil do Estado de São Paulo, São Paulo, SP Brasil)

Prof. Dr. Reginaldo Inojosa Campelo (Universidade de Pernambuco, Recife, PE Brasil)

Prof. Dr. Renato Evando Moreira Filho (Universidade Federal do Ceará, Fortaleza, CE Brasil)

Prof. Dra. Rosa Amélia Andrade Dantas (Universidade Federal do Sergipe, Aracaju, SE Brasil)

Prof. Ms. Sami Abder Rahim Jbara El Jundi (Universidade Federal do Rio Grande do Sul, Porto Alegre, RS Brasil)

Prof. Dr. Saul Pantoja Vacaflor (Sociedade Peruana de Medicina Legal, Trujillo, Peru)

Dra. Viviam Paula Lucianelli Spina (Instituto de Medicina Social de São Paulo IMESC, São Paulo, SP Brasil)

Prof. Dr. Zulmar Coutinho (Universidade Federal de Santa Catarina, Florianópolis, SC Brasil)

EDIÇÃO E PRODUÇÃO: Liege Gonzalez Jung | Indexa Editora Ltda.

DESIGN E DIAGRAMAÇÃO: André Fabro | Moiré Art

REVISÃO: Ângela Moraes

IMPRESSÃO: Ipsis Gráfica e Editora

Perspectivas em Medicina Legal e Perícias Médicas (PERSPECTIVAS) é a revista oficial da Associação Brasileira de Medicina Legal e Perícias Médicas (ABMLPM). É uma revista científica, lançada em outubro de 2016 com periodicidade quadrimestral, que tem como missão a divulgação e desenvolvimento científico da Medicina Legal e da Perícia Médica no Brasil e no mundo. Tem acesso

livre e gratuito de acordo com a licença Creative Commons e é publicada pela ABMLPM e produzida pela Indexa Editora.

\author{
ABMLPM - Associação Brasileira de Medicina Legal e Perícias Médicas - afiliada à AMB \\ Escritório Administrativo - Av. Brigadeiro Luiz Antônio, 278 - 70 andar - Bela Vista \\ São Paulo-SP CEP: 01318-901 \\ Fone: + 55 (11) 3101-5994 | Celular: + 55 (11) 97403-4818 \\ indexa@indexa.com.br
}

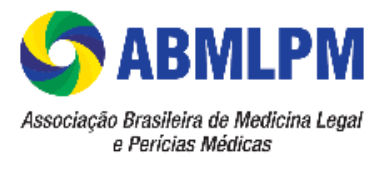


P. 6

CARTA DO PRESIDENTE LETTER FROM THE PRESIDENT Ivan Dieb Miziara

P. 7

CARTA DO EDITOR LETTER FROM THE EDITOR

José Jozefran Berto Freire

\section{ARTIGOS ORIGINAIS ORIGINAL ARTICLES}

P. 8

MORTES EVITÁVEIS: REVISÃO SISTEMÁTICA SOBRE AS DISCORDÂNCIAS DIAGNÓSTICAS CLÍNICAS E APÓS A REALIZAÇÃO DE AUTÓPSIAS

AVOIDABLE DEATHS: A SYSTEMATIC REVIEW OF DISAGREEMENTS IN CLINICAL DIAGNOSTICS AND AFTER AUTOPSIES

Autores Authors: Trunckle YF, Miziara CSMG, Muñoz DR, Miziara ID, Andreazzi IM

\section{P. 16}

LICENÇAS PARA TRATAMENTO DE SAÚDE NO TRIÊNIO 2015-2017 DE SERVIDORES NA UNIVERSIDADE FEDERAL DE SANTA MARIA, RS/BRASIL

EMPLOYEES HEALTH TREATMENT LICENSES IN THE 2015-2017

TRIENNIAL AT THE FEDERAL UNIVERSITY OF SANTA MARIA, RS/BRAZIL Autores Authors: Brum LM, Costella JS, Riesgo MN, Mentegs DCW

\section{ARTIGOS DE REVISÃO REVIEW ARTICLES}

\section{P. 24}

AGOSTINHO JOSÉ DE SOUZA LIMA E O ENSINO DA MEDICINA LEGAL AGOSTINHO JOSÉ DE SOUZA LIMA AND THE TEACHING OF LEGAL MEDICINE

Autor Author: Braga DT, Sedlmaier CE, Hernandez DP

P. 32

VIRTÓPSIA: AVANÇOS TECNOLÓGICOS EM MEDICINA LEGAL E PERÍCIA MÉDICA

VIRTÓPSIA: TECHNOLOGICAL ADVANCES IN LEGAL MEDICINE AND

MEDICAL EXPERTISE

Autor Author: Tellian N 


\section{NORMAS}

Acesse normas atualizadas e modelo de artigo em perspectivas.med.br/normas

Perspectivas em Medicina Legal e Perícias Médicas (PERSPECTIVAS) é uma revista de caráter exclusivamente científico, dedicada à divulgação e desenvolvimento científico da Medicina Legal e da Perícia Médica no Brasil e no mundo. É uma revista gratuita, de acesso aberto, publicada pela ABMLPM e editorada pela Indexa.

\section{Condições para publicação de artigos}

\subsection{Originalidade e pertinência}

Os artigos candidatos devem ser inéditos e tratar de temas em medicina legal e perícia médica ou temas afins. Devem destinar-se exclusivamente à Perspectivas em Medicina Legal e Perícias Médicas, não sendo permitida a submissão simultânea a outras publicações.

\subsection{Responsabilidade dos autores, ética e legalidade}

Ao enviar um artigo, o responsável declara ser o único autor do artigo ou ser o representante autorizado de todos os autores, ter o direito de permitir sua reprodução por terceiros, bem como a reprodução das imagens e gráficos incluídos. Em caso de artigos com mais de um autor, o responsável pela submissão deve se munir de declarações por escrito dos demais autores permitindo a submissão do manuscrito à Perspectivas. A responsabilidade por eventual infração de direitos autorais ou de imagem recai sobre o responsável pela submissão.

Os autores são responsáveis pela veracidade das informações apresentadas nos manuscritos e pelo uso de boas práticas e ética profissional nos estudos realizados. De acordo com as leis internacionais de direitos autorais, autores são responsáveis pela originalidade dos artigos e todas as suas imagens e gráficos, ou por obter permissão para reprodução e incluir os devidos créditos de imagens de autoria de terceiros, já que a reprodução de conteúdo ou ideia já antes publicada sem crédito ao autor original é considerada plágio passível de punição. Autores também são responsáveis por observar as leis de direito de imagem e devem obter permissão por escrito para incluir imagens de indivíduos e marcas registradas.

A PERSPECTIVAS segue o padrão estabelecido pelo International Comitee of Medical Journal Editors (ICMJE) por meio do documento "Requirements for manuscripts submitted to biomedical journals / "Requisitos para artigos enviados a revistas biomédicas", disponível em www.icmje.org. Suas principais diretrizes estão descritas nestas normas.

Após aprovação, o autor responsável pela submissão deverá assinar um termo de cessão de direitos autorais e ciência de responsabilidades. Este termo pode ser acessado em perspectivas.med.br/normas. O termo deve ser escaneado e enviado por e-mail em até 5 dias após a confirmação de aprovação ou em até 15 dias pelo correio.

\subsection{Conflitos de interesse}

Ao enviar um artigo, o responsável deve informar as fontes de financiamento da pesquisa. Caso exista qualquer conflito de interesse que possa ter afetado o resultado divulgado pelo artigo, este deve ser informado. Conflitos de interesse são situações em que o autor tem incentivo para divulgar resultados que melhorem a percepção do leitor sobre determinado procedimento ou medicamento. 0 incentivo pode ser de caráter comercial - patrocínio ou parceria com determinada marca ou empresa - ou pessoal - amizade ou parentesco.

\subsection{Ensaios Clínicos e experimentação humana e animal}

No Brasil, a realização de ensaios clínicos envolvendo medicamentos só é permitida mediante autorização da Anvisa por meio do registo no SISNEP - Sistema Nacional de Ética em Pesquisa - e REBEC - www.ensaiosclinicos.gov.br. Artigos incluindo ensaios clínicos devem informar o número deste registro após o resumo. 
Estudos envolvendo experimentação humana e animal devem ser acompanhados de parecer emitido por comitê de ética reconhecido pelo Conselho Nacional de Saúde (CNS).

\subsection{Cessão de direitos autorais}

PERSPECTIVAS é uma publicação de livre acesso. Para ter seu artigo publicado, autores devem aceitar as condições especificadas pela licença Creative Commons CC BY 4.0, permitindo que seu artigo seja republicado e distribuído livremente por terceiros, sem necessidade de obter prévia autorização dos autores, editores ou publicadores, sempre citando adequadamente os autores e a publicação original. Saiba mais em perspectivas.med.br/normas.

\subsection{Autores registrados nas bases Lattes e ORCID}

A partir de 2019, a Perspectivas passa a publicar apenas artigos cujos autores tenham registros nas bases acadêmicas Lattes e ORCID. Os registros são gratuitos e podem ser feitos pelos autores. Acesse os links em perspectivas.med.br/normas e registre-se.

\section{Envio}

Artigos candidatos devem ser enviados pelo e-mail liege@indexa.com.br, seguindo formato descrito abaixo. Os artigos devem ser enviados no idioma português, inglês ou espanhol, incluindo título e resumo em português e inglês. Artigos serão publicados em seus idiomas originais. Eventuais custos de tradução correm por conta do autor. Não serão aceitas traduções automáticas ou de má-qualidade.

\section{Formatação e formato}

PERSPECTIVAS aceita artigos originais de pesquisa, artigos de revisão de literatura, relatos de caso e apresentação de técnicas ou pontos de vista pessoais. Um link para baixar o artigo modelo em Word está disponível em perspectivas.med.br/normas. Todas as orientações de formato e formatação recomendados para submissões à revista Perspectivas estão indicadas nele. Favor observar a necessidade de identificação de cada autor por meio de seus registros Lattes e ORCID.

\section{Processo de seleção e revisão}

PERSPECTIVAS respeita o processo de revisão por pares pelo sistema duplo-cego simultâneo (double blind simultaneous peer review). Cada artigo recebido é triado pelo editor-chefe da revista. Se aceito, é encaminhado simultaneamente para revisão por dois peritos revisores, que aprovam ou sugerem edições ao autor. $\mathrm{O}$ autor deve responder às sugestões enviando seu artigo reeditado, que é encaminhado aos revisores originais. Estes aprovam ou sugerem novas edições. Este ciclo pode se repetir até 3 vezes. Se aprovado, é enviado à revisão ortográfica e encaminhado ao editor para encaixe na pauta de publicação.

Para garantir a imparcialidade, a revisão por pareceristas é feita "às cegas", sem identificação dos autores e estes não conhecem os nomes do revisores que avaliaram seu artigo.

O autor deve esperar receber uma resposta sobre a aprovação pela triagem em até 6 semanas a partir da data do envio. A partir da triagem, o prazo padrão para o processo de revisão e aprovação ou rejeição final é de até 6 meses.

Os principais critérios para avaliação dos artigos durante o processo de revisão são originalidade, relevância (contribuição para a especialidade), levantamento da literatura existente sobre o tema, organização e apresentação, clareza, adequação do método e de sua execução ao objetivo indicado, adequação e objetividade dos resultados.

A PERSPECTIVAS se reserva o direito de não publicar artigos recebidos, mesmo que aprovados pelos revisores.

\section{Custos de publicação e financiamento}

A publicação de artigos na PERSPECTIVAS é gratuita para autores. Os custos de produção são inteiramente financiados pela Associação Brasileira de Medicina Legal e Perícias Médicas, responsáveis pela publicação. 


\section{CARTA DO PRESIDENTE}

C

aros colegas, peritos e médicos legistas,

A 11 a edição da revista Perspectivas, orgão oficial da Associação Brasileira de Medicina Legal e Perícias Médicas, chega trazendo estudos acerca de mortes evitáveis, licenças para tratamento de saúde entre servidores da Universidade Federal de Santa Maria (RS) e também sobre avanços na prática médico-legal com o a utilização da chamada "Virtópsia".

Nesses tempos difíceis que todos estamos atravessando devido à pandemia de coronavírus que assola o mundo todo e, em particular, nosso país, é de extrema importância que continuemos (mesmo à distância) nossas atividades - em prol do enriquecimento científico de nossa especialidade, assim como buscando soluções para novos problemas que atingem a categoria de médicos legistas e peritos judiciais.

Devido às circunstâncias, fomos obrigados a transferir nosso Congresso Brasileiro que seria realizado nesse ano em Vitória (ES), para 17 a 20 de março de 2021. Foi uma medida tomada em comum acordo com nossa regional capixaba, mas que se impôs pela mínima razão de bom senso. Contamos com a presença de todos os colegas no ano que vem, na belíssima Capital do Espírito Santo.

Estamos atentos para novos desafios que vão surgir em razão dessas mesmas circunstâncias proporcionadas pela pandemia. O caro leitor encontrará também em nosso sítio na internet (www.ablpm.org.br) orientações sobre como podemos nos proteger no exercício de nossas atividades e, também, a posição de nossa Instituição (que foi encaminhada e acatada pelo Conselho Federal de Medicina) no que diz respeito à chamada "teleperícia".

Por fim, gostaríamos de agradecer a todos que colaboraram na realização dessa 11 ạ edição. Desde os autores dos trabalhos aqui publicados, passando pela equipe editorial, até seu editor José Josefran.

Uma boa leitura a todos.

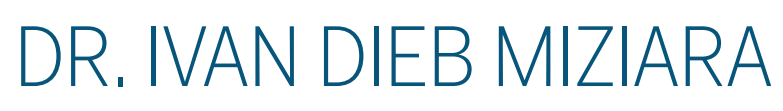




\section{CARTA DO EDITOR}

\footnotetext{
$P_{e}$
}

erspectivas ultrapassa a dezena de edições, fato a ser festejado, pois a produção de ciência publicada é algo que demanda esforço, coordenação, planejamento e vontade de pesquisar.

Nos presentes dias de pandemia, os temas sobre testes terapêuticos, busca de vacinas, estudos sobre prevenção da doença, avaliações epidemiológicas, estudos da origem da doença, etc. são o foco de publicações no planeta.

Em contrapartida as publicações sobre a nossa área de atividade científica tem uma diminuição quantitativa, perfeitamente justificável.

Por isso, o festejar a presente edição. Aqui foi tratado o ensino da Medicina

Legal sob a égide de Agostinho José de Souza Lima, atualizações sobre a Virtópsia,

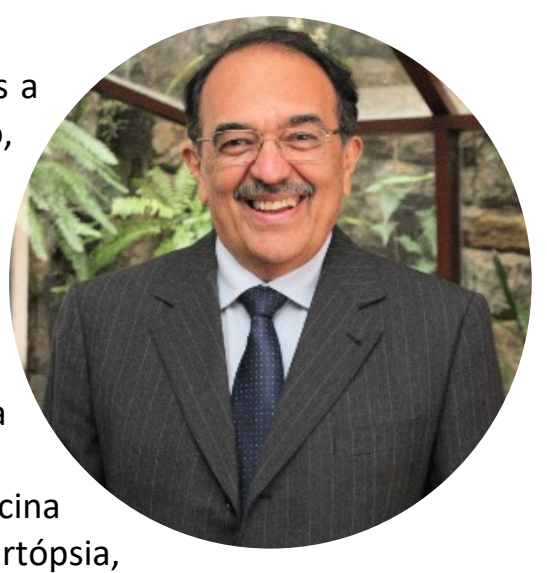
estudo estatístico sobre as mortes evitáveis e estudo também estatístico sobre as licenças médicas.

Perspectivas estimula que os milhares de colegas que exercem a especialidade, busquem compartilhar suas experiências publicando essa vivência com os demais. Ao compartilharmos nossas vivências na linguagem científica, demarcarmos cada vez mais a nossa tão importante atividade médica.

Perspectivas, aproveita essa edição para homenagear a consolidação do Mestrado em Ciências Forenses da Universidade Estadual de Pernambuco, na pessoa do Prof. Dr. Reginaldo Inojosa Carneiro Campelo. Pois, é de suma importância, a existência de cursos que permitam o aperfeiçoamento da especialidade e, ainda mais, a formação de docentes, algo tão necessário na atualidade em que esses conhecimentos são tão essenciais para vivência social sob a égide da justiça.

Perspectivas agradece de forma especial os colegas que publicaram seus trabalhos nessa edição e da mesma forma aos revisores que buscam o aperfeiçoamento das nossas sucessivas edições.

Boa leitura a todos.

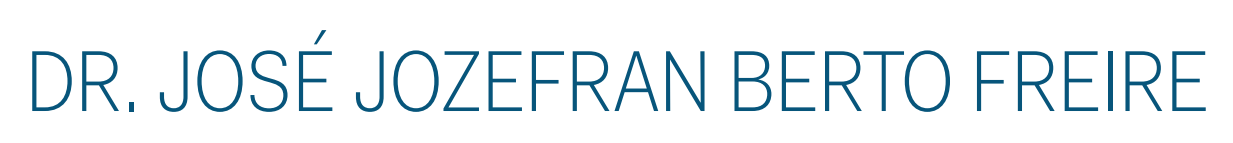

Editor - Cremesp 17288 


\section{MORTES EVTÁVEIS: REVISÃO SISTEMÁTICA SOBREAS DISCORDÂNCIAS DIAGNÓSTICAS CLINIICASE APÓS AREALIZAÇÃO DEAUTÓPSIAS}

AVOIDABLE DEATHS: A SYSTEMATIC REVIEW OF DISAGREEMENTS IN CLINICAL DIAGNOSTICS AND AFTER AUTOPSIES

ARTIGO DE REVISÃO recebido 25/02/2020 aceito em 29/02/2020

Yuri Franco Trunckle (1)

Currículo Lattes: 2180059850861759 - ID ORCID: 0000-0002-9133-9653

Carmen Silvia Molleis Galego Miziara (2)

Currículo Lattes: 6916238042273197 - ID ORCID: 0000-0002-4266-0117

Daniel Romero Muñoz (3)

Currículo Lattes: 3863004771570436 - ID ORCID: 0000-0002-4042-3070

Ivan Dieb Miziara (4)

Currículo Lattes: 3120760745952876 - ID ORCID: 0000-0001-7180-8873

Ingryd Maturo Andreazzi (5)

Currículo Lattes: 8921241226597473 - ID ORCID: 0000-0003-1478-7572

(1) Médico Residente de Medicina Legal e Perícia Médica do Departamento de Medicina Legal, Ética Médica, Medicina Social e do Trabalho da Faculdade de Medicina da Universidade de São Paulo (FMUSP), São Paulo-SP, Brasil.

(2) Professora da Disciplina de Medicina Legal e Perícia Médica da Faculdade de Medicina do ABC e da Universidade Nove de Julho, São Paulo-SP, Brasil.

(3) Professor Titular do Departamento de Medicina Legal e Perícia Médica do Departamento de Medicina Legal, Ética Médica, Medicina Social e do Trabalho da Faculdade de Medicina da Universidade de São Paulo (FMUSP), São Paulo-SP, Brasil.

(4) Professor titular da Faculdade de Medicina do $A B C$ e professor associado do Departamento de Medicina Legal, Ética Médica, Medicina Social e do Trabalho da Faculdade de Medicina da Universidade de São Paulo (FMUSP), São Paulo-SP, Brasil.

(5) Médica Residente de Medicina Legal e Perícia Médica do Departamento de Medicina Legal, Ética Médica, Medicina Social e do Trabalho da Faculdade de Medicina da Universidade de São Paulo

(FMUSP), São Paulo-SP, Brasil.

e-mail: yuriftrunckle@gmail.com

\section{RESUMO}

Introdução: mortes evitáveis são aquelas passíveis de prevenção total ou parcialmente pelo serviço de saúde. Apesar dos avanços tecnológicos envolvendo a saúde, os estudos têm demonstrado que há divergências diagnósticas clínicas e post mortem. Este estudo visa correlacionar os diagnósticos clínico e anatomopatológico obtidos por meio da análise de estudos já realizados na literatura, a fim de determinar a frequência com que a necropsia revela diagnósticos inesperados. Método: revisão sistematizada da literatura por meio de busca na base de dados MEDLINE utilizando a estratégia de busca "cause of death" [Mesh]) AND "medical errors" [Mesh]) AND "autopsy" [Mesh]. Resultados: foram incluídos 27 artigos de estudos retrospectivos e revisões sistemáticas que atendem aos critérios de inclusão, havendo uma variação de $6 \%$ a $82,3 \%$ de discordâncias 
diagnósticas encontradas. Conclusão: apesar de os índices variarem, pode-se inferir que há discordâncias diagnósticas encontradas nos estudos retrospectivos e revisões sistemáticas realizadas até então, necessitando maior correlação com os efeitos de litigância quanto à má prática médica.

Palavras-chave: autópsia, erro de diagnóstico apresentado, causas de morte.

\section{ABSTRACT}

Introduction: avoidable deaths are those totally or partially preventable by the health service. Despite technological advances in health, studies have shown that there are clinical and post-mortem diagnostic divergences. This study aims to correlate the clinical and pathological diagnoses obtained through the analysis of studies already carried out in the literature, in order to determine the frequency with which the necropsy reveals unexpected diagnoses. Method: Systematic review of the literature by searching the MEDLINE database using the search strategy "Cause of Death" [Mesh]) AND "Medical Errors" [Mesh]) AND "Autopsy" [Mesh]. Results: Twenty-seven articles of retrospective studies and systematic reviews that met the inclusion criteria were included, with a variation from $6 \%$ to $82.3 \%$ of the diagnostic disagreements found. Conclusion: Although the indices vary, it can be inferred that there are diagnostic disagreements found in the retrospective studies and systematic reviews carried out until then, requiring a greater correlation with the litigation effects of poor medical practice.

Keywords: autopsy, diagnostic error displayed, causes of death.

\section{INTRODUÇÃO}

Sabe-se que a definição de mortes evitáveis compreende aquelas que são preveníveis, total ou parcialmente, por ações efetivas dos serviços de saúde (1). Essas causas devem ser atualizadas conforme a evolução do conhecimento médico e do surgimento de novas tecnologias para o tratamento das moléstias (1). Portanto, esta revisão sistemática da literatura visa comparar os resultados encontrados por estudos retrospectivos e revisões sistemáticas já realizadas sobre o tema.

Por ser uma área que faz a sobreposição entre a Medicina e o Direito, o campo de atuação da Medicina Legal e Perícia Médica abrange as perícias médicas, sejam elas judiciais ou extrajudiciais (2) e a alegação de erro médico corresponde a uma das maiores demandas das perícias cíveis realizadas (3). O pressuposto da responsabilidade civil subjetiva do médico deve obedecer a quatro princípios: ato ilícito; culpa; nexo causal; e dano (4). A culpa seria, em sentido estrito, a vontade de praticar a conduta, mas não o resultado obtido, sendo assim muito associada ao descumprimento do dever de diligência ou cuidado e aos elementos que configuram a culpa: conduta voluntária e resultado involuntário; previsão ou previsibilidade; falta de cautela, cuidado, diligência.
Quanto à previsibilidade, é a condição em que há a probabilidade de algo acontecer, podendo ser objetiva ou subjetiva. Na primeira, é considerada a atitude de "homem médio" (aquele entre o com grau de conhecimento elevado, para além daqueles com quem convivem, e os desprovidos de instrução ínfima) e, na segunda, a situação em que o agente causador do dano estava no momento da ação ou omissão causadora do dano (5).

O Código de Defesa do Consumidor estabelece a relação entre o médico e o paciente sendo a atividade médica ser, indiretamente, considerada "serviço" e o paciente passa a ser entendido na sua vulnerabilidade técnica como "consumidor". (Lei no 8.078, de 11/9/1990. DOU Brasília, 12 de setembro de 1990).

O dano ao paciente pode ser provocado por negligência, imprudência e imperícia. Entende-se por imperícia a falta de habilidade ou experiência reputada necessária para a realização de certas atividades e cuja ausência, por parte do agente, o faz responsável pelos danos ou ilícitos penais advenientes (6). Imprudência é a falta de atenção, imprevidência, descuido. Resulta da imprevisão do agente ou da pessoa, em relação das consequências de seu ato ou ação, quando devia e podia prevê-las 
(6). E a negligência é desprezar, desatender e não cuidar. Exprime a desatenção, a falta de cuidado ou de precaução com que se executam certos atos (6). Pode-se classificar as mortes evitáveis em quatro grupos, segundo medidas de intervenção: prevenção primária, atenção médica definida por óbitos evitáveis por diagnóstico e tratamento precoce, saneamento ambiental e medidas mistas que compreendem os óbitos evitáveis por meio da aplicação de medidas mais complexas, combinando serviços médicos e ações socioeconômicas (7).

As causas de óbito mal definidas no Brasil são preocupantes devido à alta taxa de incidência que vem apresentando, pois indicam problemas de acesso e qualidade da assistência médica recebida pela população, além de comprometerem a fidedignidade das estatísticas de mortalidade por causas (8-10). Esses óbitos correspondiam a 14,3\% do total em 2000, com grande variabilidade entre municípios e mesmo regiões, com proporções variando de $28,4 \%$ no Nordeste a $6,3 \%$ no Sul (11). $\mathrm{Na}$ clínica médica, a conduta diante de quadros graves, como infarto agudo do miocárdio, faz toda diferença para o prognóstico do paciente (12-14), assim como o tratamento adequado e as medidas preventivas relacionadas à infecção (15).

$\mathrm{Na}$ clínica cirúrgica, a abordagem deve abranger tanto os casos de cirurgias eletivas e suas complicações, como as cirurgias de urgência e os fatores que influenciam no mau prognóstico dos pacientes (16-18).

O perfil dos médicos no atendimento hospitalar varia de acordo com o setor, ano de formação, idade, qualificação profissional, tempo em serviço, tempo de privação de sono, entre outros (19. São fatores que contribuem para a variação da estatística com relação à concordância dos diagnósticos clínico e anatomopatológico.

O avanço da medicina e da tecnologia diagnóstica complementar fazem com que o valor do exame necroscópico venha sendo questionado, levando ao declínio do procedimento (20). Mesmo assim, a discordância entre os diagnósticos clínico e anatomopatológico post mortem tem sido amplamente discutida (21-23).

O método utilizado por Goldman et al para avaliar a concordância entre os diagnósticos clínicos e os achados anatomopatológicos é composta por cinco classes (24):
- Classe 1: diagnóstico principal discordante, com potencial impacto na sobrevida do paciente;

- Classe 2: diagnóstico principal discordante, sem e/ou com questionável impacto na sobrevida do paciente;

- Classe 3: diagnósticos secundários não formulados, mas que contribuíram para o óbito do paciente;

- Classe 4: diagnósticos secundários não formulados, mas que não contribuíram para o óbito do paciente;

- Classe 5: concordância completa entre as hipóteses de diagnóstico clínico e os achados anatomopatológicos.

Portanto, este estudo visa correlacionar os diagnósticos clínico e anatomopatológico obtido por meio da análise de estudos já realizados na literatura, a fim de determinar a frequência com que a necropsia revela diagnósticos inesperados.

\section{MATERIAL E MÉTODO}

\subsection{DESENHO DE ESTUDO}

O desenho de estudo desta pesquisa foi uma revisão de estudos retrospectivos e de revisões sistemáticas da literatura disponíveis no que dizem respeito a discrepâncias diagnósticas clínicas e necroscópicas. Foram definidas como mortes evitáveis aquelas que ocorrem por discrepância entre os diagnósticos clínico e necroscópico.

\subsection{ESTRATÉGIA DE BUSCA}

A pesquisa foi realizada pelos autores, com restrição de linguagem para idiomas: português, inglês e espanhol.

A base primária de dados utilizada foi o MEDLINE, sendo feita a busca por publicações até novembro de 2018. Somente foram adicionadas pesquisas publicadas em jornais científicos.

Os descritores MESH de pesquisa utilizados foram: "Cause of death", "Medical errors" e "Autopsy". Todos os descritores foram utilizados junto com o operador booleano "AND" ("Cause of Death" [Mesh]) AND "Medical Errors" [Mesh]) AND "Autopsy" [Mesh]).

\subsection{SELEÇÃO DE ARTIGOS}

Os critérios de inclusão dos artigos resgatados em busca no MEDLINE incluem: 
- Primariamente, estudos com títulos compatíveis à questão;

- Secundariamente, avaliação dos resumos disponíveis;

- Estudos com acesso gratuito e na íntegra;

- Estudos apenas em seres humanos.

Os critérios de exclusão foram:

- Séries de casos, relatos de caso e cartas editoriais;

- Estudos que não são gratuitos;

- Artigos que não dispunham de resumo.

\section{RESULTADOS}

Foram encontrados por meio da estratégia de busca 230 artigos dos quais 24 foram selecionados por atenderem aos critérios de inclusão, por meio de busca realizada na base de dados MEDLINE. Os artigos abrangem o período de 1993 a 2018. Foram analisados estudos retrospectivos e revisões sistemáticas. A grande maioria deles usou a classificação de Goldman para dividir discrepâncias diagnósticas encontradas.

Houve um padrão detectado de discrepâncias diagnósticas envolvendo doenças infectocontagiosas como principal causa $(22,25-$ 30). Destes, Mort et al e Sarode et al destacam como causas principais as infecções fúngicas não diagnosticadas, assim como endocardites bacterianas.

Em outros estudos, houve como maior causa de discordâncias diagnósticas as doenças cardiovasculares, principalmente infarto agudo do miocárdio e tromboembolismo pulmonar $(21,23$, 31-36).

Dois estudos fizeram a comparação entre diagnósticos clínicos e após a autópsia em pacientes transplantados, sendo que um deles detectou que os pacientes transplantados tendem a ter maiores discrepâncias diagnósticas (37), o que entra em concordância com Seftel et al, sendo este mais específico para transplantes de medula óssea.

Von Dessauer et al analisaram especificamente na população pediátrica as discrepâncias diagnósticas encontradas após autópsias, tendo $16 \%$ de discordâncias (classes I e II de Goldman) (38). Carlotti et al analisaram crianças especificamente cirúrgicas, tendo encontrado em $22,8 \%$ erros classe I e II envolvendo principalmente erros de técnica cirúrgica e doenças infecciosas, respectivamente (39).

Dois estudos em específico avaliaram pacientes do setor de emergência, dos quais ambos observaram erros classe I e II $(22,33)$. Entretanto, O'Connor et al constataram que, apesar dos desafios da prática médica no setor de emergência, a quantidade de erros classe I foi mínima.

Foram incluídas duas revisões sistemáticas da literatura sendo elas concordantes com a necessidade de autópsias como padrão ouro nos diagnósticos de morte $(21,40)$, visto que Shojania et al constataram a média de $23,5 \%$ de discordâncias, dos quais $9 \%$ foram classe I de Goldman, indo em confluência com os achados de Roulson et al, que encontrou $10-13 \%$ de mortes potencialmente evitáveis.

Coradazzi et al encontraram resultados de 168 iatrogenias em sua amostra de 252 autópsias em decorrência do uso de sondas nasogástricas, nasoenterais, vesicais e cateteres venosos, correspondendo a $2,4 \%$ de causas diretas destas mortes (41).

Importante destacar os achados de Casali et al, estudo italiano que, apesar de ter como escopo a litigância envolvida em casos de má prática médica na Itália, também fez análises de autópsias comparando resultados clínicos e necroscópicos. Das 81 autópsias realizadas por suspeitas de má prática médica, 49 (69\%) esclareceram o diagnóstico. Destas, apenas oito confirmaram danos associados aos cuidados à saúde, concluindo que, na maioria dos casos, a necropsia revelou ausência de má prática médica (42).

Entretanto, He et al, que também fizeram a comparação entre casos de má prática médica e erros diagnósticos constatados em necropsias, observaram que a correlação entre má prática médica efetiva e discrepâncias diagnósticas estão sempre associadas (43).

Importante destacar o estudo suíço que detectou diminuição na ocorrência de discordâncias tipo I e II nos anos 2000 , reduzindo de $30 \%$ para $7 \%$ com significância estatística $(p<0.001)(44)$. Os alemães encontraram resultados semelhantes, com redução de 15,1\% para discrepâncias tipo I no período de 1988 a 2008 (45).

Analisando numericamente as porcentagens de discordâncias obtidas nos estudos analisados, tem- 
se uma variação ampla de $6-82,3 \%$ com destaque para Seftel et al, que analisaram pacientes transplantados, e Tavora et al, nos pacientes exclusivamente cirúrgicos com $64 \%$ e 50\%, respectivamente. Por outro lado, Carvalho et al e Silfvast et al encontraram $64 \%$ e $94 \%$ de concordâncias, respectivamente. A Tab. 1 presente no anexo discrimina as discordâncias e populações estudadas.

\section{DISCUSSÃO}

As discordâncias diagnósticas encontradas nos estudos selecionados sistematicamente apresentam grande variação em ocorrência e se deve levar em conta particularidades de cada um, logo que dois deles avaliaram especificamente a população pediátrica $(38,39)$ o que muda o espectro de doenças acometidas, além de pacientes transplantados que apresentam maiores complicações infecciosas $(26,37)$, especialmente as fúngicas e as de caráter autoimune, no que diz respeito a rejeições.

As complicações infecciosas são as mais comumente encontradas nas autópsias, indicando maior dificuldade no diagnóstico clínico tendo em visto a ampla forma de apresentação dessas enfermidades, seguidas de doenças cardiovasculares, como o infarto agudo do miocárdio e o tromboembolismo pulmonar. A dificuldade diagnóstica dessas doenças provavelmente se deve às suas causas multifatoriais, bem como as suas letalidades.

Selfvast et al destaca que os pacientes foram tratados com medicamentos vasoativos, podendo ser a causa ou estarem associados a outros fatores que levaram aos infartos agudos do miocárdio. Esse aspecto ilustra a complexidade desses casos em que houve discordância diagnóstica, pois são de difícil detecção e controle, mesmo com as tecnologias atuais.

Da mesma forma, temos as altas taxas de infecções não diagnosticadas clinicamente, como as fúngicas e as endocardites bacterianas $(25,30)$, as quais sabidamente são desafiadoras e de potencial evolutivo insatisfatório quando não diagnosticadas rapidamente. Ademais, ambas são de apresentações atípicas e tidas como de diagnóstico de exclusão, tendo em vista sua menor incidência na população em geral, valendo ressaltar que, casos de infecções fúngicas, detectadas nas autópsias de indivíduos imunocomprometidos, como nos estudos de Tai et al e Seftel et al sobre pacientes transplantados, figuram epidemiologicamente como mais prevalentes nessa população.

Entretanto, vale ressaltar os achados de Liu et al e O'Connor et al, os quais confrontaram a possibilidade de pacientes do setor de emergência, pelas limitações diagnósticas clínicas e muitas vezes terapêuticas, não havendo grande quantidade de erros tipo I de Goldman nesses casos. Isso pode ser em decorrência da estrutura do serviço estudado, o que não é padrão geral, posto que se trata de uma população restrita, tornando-a um viés e necessitando de outros estudos específicos no setor, apesar de se mostrar um resultado positivo no que tange ao sucesso diagnóstico.

As duas revisões sistemáticas analisadas neste estudo chegaram a conclusões semelhantes no que diz respeito a mortes potencialmente evitáveis, visto que houve variação de discordâncias tipo I entre $10-23,5 \%$, destacando para Roulson et al, que realizaram metanálise e, portanto, maior confiabilidade estatística nos resultados encontrados nos estudos por eles analisados. Apesar de serem números em porcentagem de menor monta, há de se destacar os resultados uma vez, pois, por se tratar de mortes evitáveis, a estatística deve ser a mais baixa possível.

Nesse aspecto, os dois estudos que encontraram redução nos erros tipo I no novo milênio podem indicar auxílio diagnóstico importante das tecnologias introduzidas nos últimos anos, as quais auxiliam no esclarecimento das causas de morte $(44,45)$.

As discordâncias diagnósticas remetem a questões de litigância de má prática médica, figurando dano ao paciente, elementos objetivos que carecem de dados no meio científico. Indo ao encontro a esta questão, Casali et al encontraram números interessantes: $69 \%$ dos casos analisados foram por suspeita de danos associados aos cuidados de saúde, entretanto, não houve discordância com os resultados da autópsia, indicando baixa incidência na amostra do estudo de má prática efetiva, confrontando com os resultados do estudo chinês que encontrou forte associação (43).

Esse resultado pode servir como contraponto às crescentes questões judiciais envolvendo médicos 
e os danos associados aos cuidados de saúde, uma vez que discordâncias diagnósticas podem ocorrer, mas nem todos os casos são em decorrência de má prática médica.

É importante ressaltar que esta revisão apresenta limitações, uma vez que populações heterogêneas foram estudadas e com amostragens diferentes, resultando em prováveis vieses. Além disso, estudos em outros idiomas, que não o inglês, português e espanhol, não foram incluídos.

Apesar dessas limitações, este estudo esclarece aspectos importantes que envolvem as discordâncias diagnósticas clínicas e necroscópicas, ressaltando a necessidade de mais estudos sobre o tema e podendo confrontar com casos de litigância contra serviços de saúde, promovendo dados estatísticos mais confiáveis.

\section{DISCUSSÃO}

A DF é uma doença com alta prevalência na Tendo em vista os achados encontrados neste estudo, pode-se inferir que há discordâncias diagnósticas encontradas nos estudos retrospectivos e de revisão sistemática sobre o tema até então, com destaque para doenças infectocontagiosas e cardiovasculares. Por sua vez, trata-se de estatísticas relativamente baixas e que necessitam maior confrontação com análises de litigância sobre danos associados aos cuidados de saúde de modo a esclarecer se há ou não, nessas discordâncias encontradas, de fato, má prática médica, uma vez que os dois artigos analisando esse aspecto, incluídos neste estudo, apresentaram resultados divergentes.

\section{ANEXO}

\begin{tabular}{|c|c|c|c|}
\hline Referência & Período & População & Discordâncias \\
\hline Roulson et al & $1972-2002$ & $\begin{array}{l}\text { Adultos, geriátricos e } \\
\text { pediátricos }\end{array}$ & $15-41 \%$ \\
\hline Liu et al & 2001-2015 & Setor de emergências & $60,7 \%$ \\
\hline Issa et al & $2000-2005$ & Insuficiência cardiaca & $82,3 \%$ \\
\hline Sarode et al & 1983-1988 & Adultos & $52 \%$ \\
\hline Seftel et al & $1990-2004$ & Transplantados & $64 \%$ \\
\hline Marshall et al & $2009-2014$ & Adultos & $19,5 \%$ \\
\hline Pastores et al & $1999-2005$ & Neoplásicos & $26 \%$ \\
\hline Silfvast et al & $1996-2000$ & Adultos-UTI & $6 \%$ \\
\hline Mort et al & $1989-1998$ & $\begin{array}{l}\text { Adultos, geriátricos e } \\
\text { pediátricos }\end{array}$ & $41 \%$ \\
\hline Tavora et al & $\begin{array}{l}1999-2005 \text { e } 2002- \\
2006\end{array}$ & Adultos & $50 \%$ \\
\hline Spiliopoulou et al & $1999-2003$ & Adultos & $19 \%$ \\
\hline O'Connor et al & 1999-2001 & Setor de emergências & $7 \%$ \\
\hline Perkins et al & 1998-2001 & Adultos & $26 \%$ \\
\hline Carvalho et al & $2000-2001$ & Adultos & $36 \%$ \\
\hline Ornelas-Aguirre et al & 1986-1992 & Adultos-UTI & $41 \%$ \\
\hline Tai et al & 1994-1995 & Transplantados & $19,8 \%$ \\
\hline von Dessauer et al & $2000-2005$ & Pediátricos-UTI & $16 \%$ \\
\hline Carlotti et al & 2011-2015 & Pediátricos-UTI & $22,8 \%$ \\
\hline Shojania et al & $1966-2002$ & $\begin{array}{l}\text { Adultos, geriátricos e } \\
\text { pediátricos }\end{array}$ & $32,5 \%$ \\
\hline Coradazzi et al & $\begin{array}{l}1975-1982 \text { e } 1992- \\
1996\end{array}$ & Adultos & $6-11 \%$ \\
\hline Casali et al & $1996-2009$ & $\begin{array}{l}\text { Adultos, geriátricos e } \\
\text { pediátricos }\end{array}$ & $12,7 \%$ \\
\hline He et al & $2004-2013$ & $\begin{array}{l}\text { Adultos, geriátricos e } \\
\text { pediátricos }\end{array}$ & $35,7 \%$ \\
\hline Schwanda-Burger et al & 2002 & Adultos-UTI & $7 \%$ \\
\hline Wittschieber et al & $\begin{array}{l}1988,1993,1998,2003 \\
\text { e } 2008\end{array}$ & Adultos & $27,1 \%$ \\
\hline
\end{tabular}

\section{REFERÊNCIAS}

1. Malta DC, Duarte EC, Almeida MF, Dias MAS, Morais Neto OL, Moura L et al. Lista de causas de mortes evitáveis por intervenções do Sistema Único de Saúde do Brasil. Epid Serv Saúde. 2007; 16(4): p233-244.

2. Muñoz DR, Muñoz-Gianvecchio D, Gianvecchio VAP. Momento histórico de uma especialidade. Saúde Ét Just. 2010; 15(2): p69-74.

3. Abate A. O erro médico. Neg Saúde. 2006; 35(1): p1-5.

4. Gonçalves CR. Responsabilidade civil. 14ed. São Paulo: Saraiva; 2012.

5. Santana SP. A culpa temerária: contributo para uma construção no direito penal brasileiro. São Paulo: Revista dos Tribunais; 2005.

6. Stedman. Dicionário Médico. 2003; p27.

7. Kanso S, Romero DE, Leite IC, Marques A. Brasil: análise das principais causas de morte. Cad Saúde Púb. 2013; 29(4): p735-774.

8. Laurenti R, Mello Jorge MHP, Gotlieb SL. A contabilidade dos dados de mortalidade $\mathrm{e}$ morbidade por doenças crônicas nãotransmissíveis. Ciênc Saúde Col. 2004; 9(4): p909921.

9. Mello Jorge MHP, Gotlieb SLD, Laurenti R. O sistema de informações sobre mortalidade: problemas e propostas para o seu enfrentamento I 
- Mortes por causas naturais. Rev Bras Epid. 2002; 5(2): p197-223.

10. Teixeira CLS, Klein CH, Bloch KV, Coeli CM. Reclassificação dos grupos de causas prováveis dos óbitos de causa mal definida, com base nas Autorizações de Internação Hospitalar no Sistema Único de Saúde, Estado do Rio de Janeiro, Brasil. Cad Saúde Púb. 2006; 22(6): p1315-1324.

11. Ministério da Saúde. Datasus. Brasília (DF); [s.d.] [citado jun. 2013]. Disponível em: www.datasus.gov.br.

12. Conterno LO, Barbosa RWN, Rego CM, Silva Filho CR. Gravidade do déficit neurológico e incidência de infecções em pacientes idosos com acidente vascular cerebral agudo. Sci Med. 2016; 26(4): ID25168.

13. Gnatta JR, Balsamo AC, Silveira IR, Padoveze MC. Características de pneumonias hospitalares em pacientes sem ventilação mecânica. J Infect Control 2014; 3(2): p32-35.

14. Jorge MHPM. Gastos governamentais do SUS com internações hospitalares por causas externas: análise no Estado de São Paulo em 2000. Rev Bras Epidemiol. 2004; 7(2): p228-238.

15. Brant LCC, Nascimento BR, Passos VMA, Duncan $B B$, Bensenõr IJM, Malta DC et al. Variações e diferenciais da mortalidade por doença cardiovascular no Brasil e em seus estados, em 1990 e 2015: estimativas do Estudo Carga Global de Doença. Rev Bras Epid. 2017; 20(1): p116-128.

16. Malta DC, Moura L, Prado RR, Escalante JC, Schmidt MI, Duncan BB. Mortalidade por doenças crônicas não transmissíveis no Brasil e suas regiões, 2000 a 2011. Epid Serv Saúde. 2014 out-dez; 23(4): p599-608.

17. Pereira KSM, Oliveira JCP, Carvalho FCC, Bellen BV. Complicações cardíacas em cirurgia vascular. J Vasc Bras. 2016; 15(1): p16-20.

18. Siqueira EMP, Diccini S. Complicações pósoperatórias em neurocirurgia eletiva e não eletiva. Acta Paul Enferm. 2017; 30(1): p101-108.

19. Almeida MC, Couto LAAM, Silva LHF, Carvalhal SS. Correlação diagnóstica anatomoclínica. Aferição retrospectiva do diagnóstico clínico em necropsias. Rev Saúde Públ. 1989; 23(4): p285-291.

20. Steigman CK. The autopsy as a quality assurance tool: last rites or resurrection? Arch Pathol Lab Med. 1996; 120: p736-738.

21. Roulson J, Benbow EW, Hasleton PS.
Discrepancies between clinical and autopsy diagnosis and the value of post mortem histology: a meta-analysis and review. Histop. 2005; 47(6): p551-559.

22. Liu D, Gan R, Zhang W, Wang W, Saiyin H, Zeng $W$ et al. Autopsy interrogation of emergency medicine dispute cases: how often are clinical diagnoses incorrect? J Clin Pathol. 2018 Jan; 71(1): p67-71. doi: 10.1136/jclinpath-2017-204484. [Epub 2017 July 22[.

23. Issa VS, Dinardi LFL, Pereira TV, Almeida LK, Barbosa TS, Benvenutti LA et al. Diagnostic discrepancies in clinical practice: an autopsy study in patients with heart failure. Med. 2017; 96(4): e5978. doi:10.1097/MD.0000000000005978.

24. Goldman L, Sayson R, Robbins S, Cohn LH, Bettmann $M$, Weisberg $M$. The value of the autopsy in three medical eras. N Engl J Med. 1983; 308: p1000-1005.

25. Sarode VR, Datta BN, Banerjee AK, Banerjee CK, Joshi K, Busnurmath B, Radotra BD. Autopsy findings and clinal diagnoses: A review of 1,000 cases. Hum Path. 1993; 24(2), p194-198.

26. Seftel MD, Ho M, Pruthi D, Orbanski S, Rubinger $M$, Schacter $B$, et al. High rate of discordance between clinical and autopsy diagnoses in blood and marrow transplantation. Bone Marrow Transp. 2007; 40: p1049-1053.

27. Marshall HS, Milikowski C. Comparison of clinical diagnoses and autopsy findings: six-year retrospective study. Arch Path Lab Med. 2017; 141(9): p1262-1266.

28. Pastores SM, Dulu A, Voigt L, Raoof N, Alicea M, Halpern NA. Premortem clinical diagnoses and post-mortem autopsy findings: discrepancies in critically ill cancer patients. Crit Care. 2007, 11(2): R48.

29. Silfvast T, Takkunen O, Kolho E, Andersson LC, Rosenberg P. Characteristics of discrepancies between clinical and autopsy diagnoses in the intensive care unit: a 5-year review. Intens Care Med. 2003; 29: p321-324

30. Mort TC, Yeston NS. The relationship of pre mortem diagnoses and post mortem findings in a surgical intensive care unit. Crit Care Med. 1999; 27(2): p299-303.

31. Tavora F, Crowder CD, Sun CC, Burke AP. Discrepancies between clinical and autopsy diagnoses: a comparison of university, community, 
and private autopsy practices. Am J Clin Pathol. 2008; 129(1): p102-109.

32. Spiliopoulou C, Papadodima S, Kotakidis N, Koutselinis A. Clinical diagnoses and autopsy findings: a retrospective analysis of 252 cases in Greece. Arch Pathol Lab Med. 2005; 129(2): p210214.

33. O'Connor AE, Jeremy TP, Richardson DB, Jain S, Herdson PB. A comparison of the antemortem clinical diagnosis and autopsy findings for patients who die in the emergency department. Acad Emerg Med. 2002; 9(9): p957-959.

34. Perkins GD, McAuley DF, Davies S, Gao F. Discrepancies between clinical and postmortem diagnoses in critically ill patients: an observational study. Crit Care 2003; 7: R129-R132.

35. Carvalho FLP, Cordeiro JA, Cury PM. Clinical and pathological disagreement upon the cause of death in a teaching hospital: analysis of 100 autopsy cases in a prospective study. Path Intern 2008; 58: p568571.

36. Ornelas-Aguirre JM, Vázquez-Camacho G, Gonzalez-Lopez L, Garcia-Gonzalez A, Gamez-Nava JI. Concordance between premortem and postmortem diagnosis in the autopsy: results of a 10 -year study in a tertiary care center. Ann Diag Path. 2003; 7(4): p223-230.

37. Tai DYH, El-Bilbeisi H, Tewari S, Mascha EJ, Wiedemann HP, Arroliga AC. A study of consecutive autopsies in a medical ICU* a comparison of clinical cause of death and autopsy diagnosis. Chest. 2001; 119(2): p530-536.

38. von Dessauer B, Velozo L, Benavente C, Bobenrieth F, Bongain J, Irazuzta J. Postmortem studies in the contemporary pediatric intensive care unit. Pediatr Crit Care Med. 2011; 12(6): p617-21. doi: 10.1097/PCC.0b013e3182071266.

39. Carlotti APCP, Bachette LG, Carmona F, Manso $\mathrm{PH}$, Vicente WV, Ramalho FS. Discrepancies between clinical diagnoses and autopsy findings in critically III children: a prospective study. Am J Clin Pathol. December 2016; 146: p701-708.

40. Shojania KG, Burton EC, McDonald KM, Goldman L. Changes in rates of autopsy-detected diagnostic errors over time: a systematic review. JAMA. 2003; 289(21): p2849-2856.

41. Coradazzi AL, Morganti ALC, Montenegro MRG. Discrepancies between clinical diagnoses and autopsy findings. Braz J Med Biol Res. 2003; 36: p385-391.

42. Casali MB, Mobilia F, Del Sordo S, Blandino A, Genovese U. The medical malpractice in Milan-Italy. A retrospective survey on 14 years of judicial autopsies. Forensic Sci Intern. 2014; 242: p38-43. 43. He F, Li L, Bynum J, et al. Medical malpractice in Wuhan, China: a 10 year autopsy-based singlecenter study.

44. Schwanda-Burger S, Moch H, Muntwyler J, Salomon F. Diagnostic errors in hte new millennium: a follow-up autopsy study. Mod Path. 2012; 25: p777-783.

45. Wittschieber $D$, Klauschen F, Kimmritz AC, von Winterfeld M, Kamphues C, Scholman HJ, et al. Who is at risk for diagnostic discrepancies? Comparison of pre- and postmortal diagnoses in 1800 patients of 3 medical decades in East and West Berlin. PLoS One. 2012; 7(5): e37460. 


\title{
LICENÇAS PARA TRATAMENTO DE SAÚDE NO TRIÊNIO 2015-2017 DE SERVIDORES NA UNIVERSIDADE FEDERAL DE SANTA MARIA, RS/BRASIL
}

\author{
EMPLOYEES HEALTH TREATMENT LICENSES IN THE 2015-2017 TRIENNIAL AT THE FEDERAL UNIVERSITY OF \\ SANTA MARIA, RS/ BRAZIL
}

ARTIGO ORIGINAL recebido 5/7/2019, aceito em 26/8/2019

Liliani Mathias Brum $^{(1)}$
Currículo Lattes: 7307119282007900 - ID ORCID: 0000-0002-4205-8871
Jonas Severino Costella
(2)
Currículo Lattes: 4329811788488375 - ID ORCID: 0000-0001-6863-9597
Manuela Nunes Riesgo
Currículo Lattes: 9383810172222475 - ID ORCID: 0000-0002-5658-7432
Dara Christy Werle Mentegs
Currículo Lattes: 3509860659666869 - ID ORCID: 0000-0002-3726-7660

(1) Médica do Trabalho. Especialista em Medicina Legal e Perícias Médicas. Doutora em Educação em Ciências: Química da Vida e Saúde/UFSM. Docente do Curso de Medicina da Universidade Franciscana. Coordenadora do Serviço de Perícia Oficial em Saúde da UFSM/RS

(2) Estudante do Curso de Medicina da Universidade Franciscana, Santa Maria/RS e-mail: jonas.costella@gmail.com

\section{RESUMO}

O estudo das principais doenças que afastam os servidores públicos civis de suas atividades laborais consiste em um desafio necessário para prevenção de doenças e promoção da saúde nas instituições federais. Este estudo teve como objetivo analisar as principais causas de afastamentos do trabalho dos servidores da UFSM, no triênio 2015-2017. Trata-se de uma pesquisa documental e descritiva, em que foram avaliadas as licenças para tratamento de saúde, durante o referido período, concedidas aos servidores da UFSM, utilizando-se a base de dados institucional. Detectou-se que os Transtornos Mentais e Comportamentais prevaleceram como causa de afastamentos do trabalho entre os servidores da instituição, seguidos pelas Doenças Osteomusculares e Doenças do Sistema Respiratório. A faixa etária mais acometida por doenças foi entre 48 a 57 anos de idade e pessoas do sexo feminino estiveram mais afastadas do trabalho durante o período analisado. As informações encontradas neste estudo apontam para a necessidade urgente de planejamento, desenvolvimento e implementação da Política de Atenção à Saúde do Servidor (PASS). A prevalência de transtornos mentais e comportamentais encontrada nesta investigação alerta para a magnitude do problema e da necessidade de melhores condições psicossociais no trabalho. Estes dados alertam para que medidas de promoção de saúde mental sejam melhoradas e efetivas no setor público federal.

Palavras-chave: doenças e trabalho, LTS, afastamentos, saúde dos trabalhadores. 


\begin{abstract}
The study of the major diseases that distract civil servants from their work activities is a necessary challenge for disease prevention and health promotion in federal institutions. The aim of this study was to analyze the main causes of working leave for healthing care licenses granted to the UFSM's servers during the period from 2015 to 2017. It is a documentary and descriptive research on the health care licenses granted to the UFSM's servers during the period from 2015 to 2017. It was evaluated using the institutional database. It was found that Mental and Behavioral Disorders prevailed as a cause of work dislocation among the institution's employees, followed by Osteomuscular Diseases and Respiratory System Diseases. The age group most affected by diseases was between 48 to 57 years of age and female people moved more away from work during this period. The information found in this study points to the urgent need for planning, development and implementation of the Server Health Care Policy (PASS). The prevalence of mental and behavioral disorders found in this investigation alerts to the magnitude of the problem and the need for better psychosocial conditions at work. These data warn that mental health promotion measures are improved and effective in the federal public sector.
\end{abstract}

Keywords: diseases and work, LTS, absenteeism, workers' health.

\section{INTRODUÇÃO}

As condições sob as quais os trabalhadores mobilizam suas capacidades físicas, cognitivas e afetivas para atingir os objetivos da produção podem desencadear sobre-esforço ou hipersolicitação de suas funções psicofisiológicas, precipitando doenças que culminariam com os afastamentos do trabalho (1). A descrição de efeitos nocivos sobre a saúde, provenientes de elevados níveis de demanda e estimulação ambiental excessiva, é ampla $(2,3)$.

Conforme vamos acompanhando a tecnicidade do mundo, cada vez mais é necessário um trabalhador com maiores habilidades, ágil, que saiba lidar com uma nova representação de mundo. Essa pessoa precisa dominar sua língua, em alguns casos outro idioma, ter rapidez tanto manual, como na voz e na mente, além de uma bagagem de informação disponível enquanto recurso pessoal para, ante qualquer dificuldade, utilizá-la (4).

O absenteísmo é a ausência não prevista do funcionário causada pela sua incapacidade ao trabalho devido a algum problema de saúde (5). 0 resultado desta situação é a desorganização do serviço, uma vez que é necessário o remanejamento de pessoas de uma função para outra de forma rápida, acarretando mais estresse aos funcionários, queda da produtividade e da qualidade do serviço. Essa situação gera resultados negativos que são observados pelo agravamento dos acidentes de serviço e das doenças ocupacionais (6). Nesse contexto, este estudo objetiva analisar as Licenças para Tratamento de Saúde, no período de 20152017, concedidas aos servidores da Universidade Federal de Santa Maria, bem como verificar as patologias que mais afastam os servidores do ambiente laboral. Assim será possível planejar medidas preventivas que poderão ser realizadas a fim de proporcionar uma melhor qualidade de vida desses servidores e reduzir os afastamentos do trabalho por doenças.

\section{MATERIAL E MÉTODOS}

O presente artigo constitui uma pesquisa documental proveniente de dados secundários que podem ser localizados de forma rápida, barata e segura. (7) O relatório de dados foi emitido pela coordenação do Serviço de Perícia Oficial em Saúde da Universidade Federal de Santa Maria (UFSM), que autorizou o uso desses dados conforme os critérios éticos estabelecidos na resolução n. 0466 , de 12 de dezembro de 2012 (8). Essa pesquisa apresenta um caráter descritivo, a qual visa descrever características de determinada população ou fenômeno ou o estabelecimento de relações entre variáveis, assumindo, a forma de levantamento (9).

Para o levantamento dos dados, estabeleceu-se o período de 2015 a 2017, utilizando-se a base de dados institucional, publicados no Sistema de 
Informações para o Ensino da Instituição (SIE), para verificar, entre as Licenças para Tratamento de Saúde, quais os diagnósticos mais incidentes. Realizou-se a análise considerando as faixas etárias e o sexo onde esses afastamentos predominaram. Os dados obtidos via sistema de gerenciamento de dados da instituição UFSM publicados pelo SIE foram analisados com o programa Microsoft Excel.

\section{RESULTADOS}

Inicialmente, salienta-se a importância deste estudo pelo fato de ele ter sido realizado no âmbito de uma Instituição Federal de Ensino Superior (IFES), no caso, a Universidade Federal de Santa Maria (UFSM). Enfatiza-se que o levantamento foi feito pelo período de três anos (2015-2017), por meio de um estudo comparativo das patologias mais prevalentes como causas de afastamento do trabalho entre os servidores públicos federais da UFSM. À época da realização do estudo, a UFSM contava com um total de 4.748 servidores, entre técnicos e docentes.

$\mathrm{Na}$ análise das Licenças para Tratamento de Saúde concedidas (Fig. 1), observa-se que elas foram mais prevalentes durante esse período devido a Doenças Mentais e Comportamentais (1548-LTS), seguidas pelas Doenças do Sistema Osteomuscular e Tecido Conjuntivo (988- LTS) e Doenças do Sistema Respiratório (836- LTS), totalizando 3.372 ocorrências dessas licenças concedidas na UFSM, durante o triênio estudado. A partir dos resultados obtidos, houve uma prevalência maior de afastamentos devido a Doenças Mentais e Comportamentais.

Em ordem de ocorrência decrescente, das licenças para transtornos de saúde concedidas, foram: Transtornos mentais e comportamentais, Doenças do sistema osteomuscular e tecido conjuntivo, Doenças do aparelho respiratório, Doenças do aparelho digestivo e Fatores que influenciam no estado de saúde (Fig. 1).

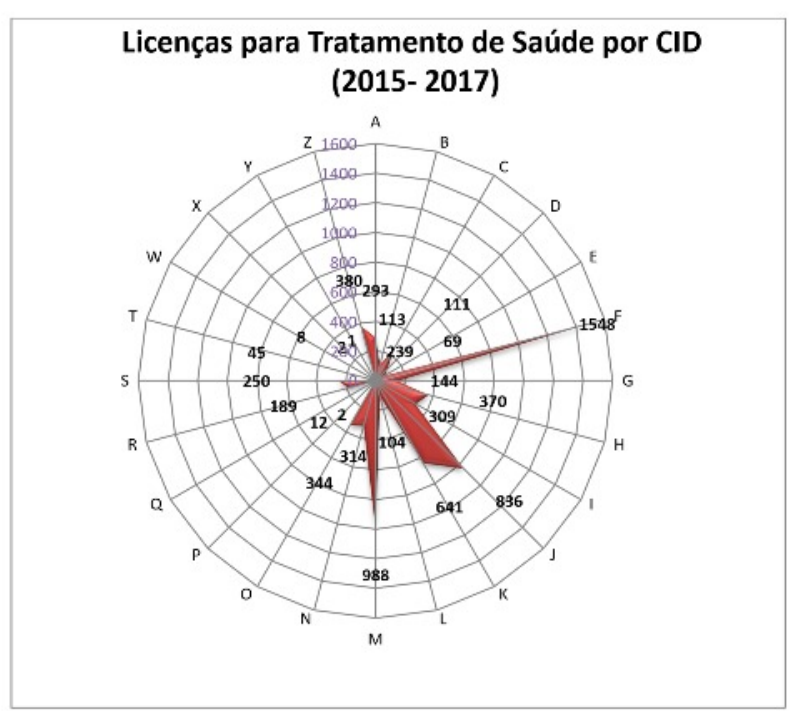

CID-10: Classificação Internacional de Doenças; CID-10.A: Doenças infecciosas e parasitárias; CID10.B: Doenças virais; CID-10. C-D: Neoplasias; CID10.E: Doenças endócrinas, nutricionais e metabólicas; CID-10.F: Transtornos mentais e comportamentais; CID-10.G: Doenças do Sistema Nervoso; CID-10.H: Doenças do olho e anexos, doenças do ouvido e da apófise mastoide. CID-10.I: Doenças do aparelho circulatório; CID-10.J: Doenças do aparelho respiratório; CID-10.K: Doenças do aparelho digestivo; CID-10.L: Doenças da pele e do tecido subcutâneo; CID-10.M: Doenças do sistema osteomuscular e tecido conjuntivo; CID-10.N: Doenças do aparelho geniturinário; CID-10.0: Gravidez, parto e puerpério; CID-10.P: Algumas afeç̧ões originadas no período perinatal; CID-10.Q: Malformações congênitas, deformidades e anomalias cromossômicas; CID-10.R: Sintomas, sinais e achados anormais de exames clínicos e laboratoriais; CID-10.S-T: Lesões, envenenamento e algumas outras consequências de causas externas; CID-10.V-Y: Causas externas de morbidade e de mortalidade; CID-10.Z: Fatores que influenciam o estado de saúde. CID-10.U: Códigos para propósitos especiais.

Fig. 1: Licenças para Tratamento de Saúde dos servidores da UFSM estratificadas por diagnósticos (conforme CID), no triênio 2015-2017. 
Na Fig. 2, verifica-se que $21 \%$ das Licenças para Tratamento de Saúde concedidas na UFSM no período estudado foram devido aos Transtornos mentais e comportamentais, $14 \%$ foram por Doenças osteomusculares e do tecido conjuntivo e $11 \%$ devido a Doenças do sistema respiratório, além de outras com menores percentuais.

Dentre as doenças do trabalho, 52,3\% foram identificadas como distúrbios osteomusculares equivalentes à LER/DORT, de acordo com a Classificação Internacional de Doenças - CID-10 (10) (Fig. 2).

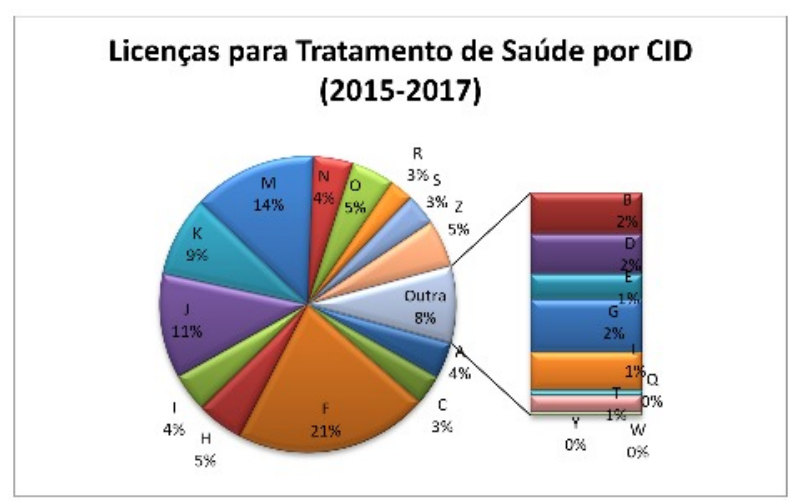

CID-10: Classificação Internacional de Doenças; CID-10.A: Doenças infecciosas e parasitárias; CID10.B: Doenças Virais; CID-10. C-D: Neoplasias; CID10.E: Doenças endócrinas, nutricionais e metabólicas; CID-10.F: Transtornos Mentais e Comportamentais; CID-10.G: Doenças do Sistema Nervoso; CID-10.H: Doenças do olho e anexos, doenças do ouvido e da apófise mastoide. CID-10.I: Doenças do aparelho circulatório; CID-10.J: Doenças do aparelho respiratório; CID-10.K: Doenças do aparelho digestivo; CID-10.L: Doenças da pele e do tecido subcutâneo; CID-10.M: Doenças do sistema osteomuscular e tecido conjuntivo; CID-10.N: Doenças do aparelho geniturinário; CID-10.0: Gravidez, parto e puerpério; CID-10.P: Algumas afeç̧ões originadas no período perinatal; CID-10.Q: Malformações congênitas, deformidades e anomalias cromossômicas; CID-10.R: Sintomas, sinais e achados anormais de exames clínicos e laboratoriais; CID-10.S-T: Lesões, envenenamento e algumas outras consequências de causas externas; CID-10.V-Y: Causas externas de morbidade e de mortalidade; CID-10.Z: Fatores que influenciam o estado de saúde. CID-10.U: Códigos para propósitos especiais.

Fig. 2: Licenças para Tratamento de Saúde dos servidores da UFSM estratificadas por diagnósticos (conforme CID), no triênio 2015-2017.

$\mathrm{Na}$ análise estratificada por sexo, no triênio 20152017, para CID-10.F: Transtornos mentais e comportamentais, a incidência no sexo feminino foi 4,5:1 quando comparada ao sexo masculino. Para CID-10.J: Doenças do aparelho respiratório, a incidência no sexo feminino foi $3,4: 1$ quando comparada ao sexo masculino, enquanto para CID-10.M: Doenças do sistema osteomuscular e tecido conjuntivo, também houve maior prevalência no sexo feminino em relação ao masculino, na proporção de 3:1 (Fig. 3).

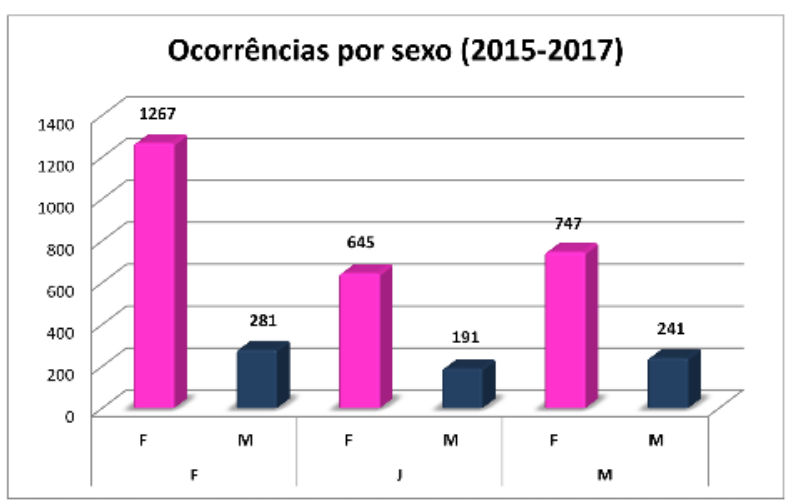

CID-10.F: Transtornos mentais e comportamentais; CID-10.J: Doenças do aparelho respiratório; CID10.M: Doenças do sistema osteomuscular e tecido conjuntivo

Fig. 3: Licenças para Tratamento de Saúde dos servidores, estratificadas por sexo no triênio 20152017, na Universidade Federal de Santa Maria.

As licenças de afastamento para tratamento de saúde foram predominantes na faixa etária de 48 a 57 anos de idade, com um total de 2.587 licenças; seguida pela faixa etária de 38 a 47 anos, com 1.807 afastamentos; faixa etária de mais de 58 anos com 1.769 afastamentos, e a faixa etária de 28-37 anos com 1.061 licenças para tratamento de saúde (Fig4). 


\section{Ocorrências por faixa etária (2015-2017)}

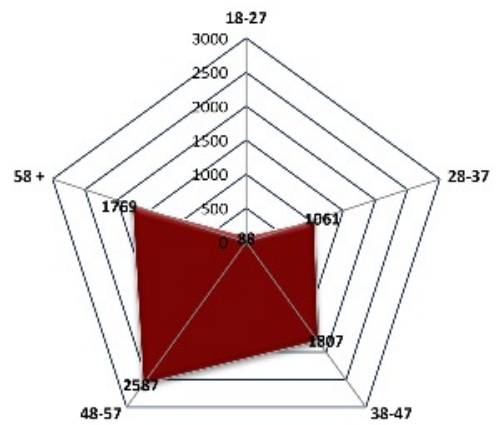

Fig. 4: Licenças para Tratamento de Saúde dos servidores, estratificadas por faixa etária no triênio 2015-2017, na Universidade Federal de Santa Maria.

\section{DISCUSSÃO}

Apesar de alguns trabalhos no Brasil apontarem como principal causa de afastamento do trabalho as doenças osteomusculares e do tecido conjuntivo, e que nos próximos anos essas patologias serão ultrapassadas pelos transtornos mentais e comportamentais (11), na UFSM essa situação já se tornou realidade, pois são as doenças mentais que mais afastaram os servidores nos últimos três anos. Faz-se importante ressaltar que, em relação à presença de comorbidade, há maior risco de afastamento do trabalho quando existem concomitantemente ansiedade e depressão, representando um impacto negativo tanto para o trabalhador quanto para seu empregador, em virtude do absenteísmo, da queda de produtividade e da alta rotatividade de profissionais (12). A partir do exposto, fica evidente que os transtornos de humor estão associados diretamente ao comprometimento do trabalho. Assim, melhorar o acesso aos cuidados e aumentar a deteç̧ão precoce e manejo de transtornos mentais devem ser uma prioridade para o país, possibilitando um papel fundamental no aumento da produtividade dos trabalhadores brasileiros (13).

Dados da Secretaria de Previdência mostram que as concessões de auxílio-doença por transtornos de ansiedade cresceram $17 \%$ em quatro anos. Passaram de 22,6 mil, em 2012, para 26,5 mil, em 2016. A ansiedade já responde por dois em cada dez afastamentos por transtornos mentais e comportamentais. Fica atrás apenas da depressão, que responde por três em cada dez concessões nesse tipo de benefício. Para alguns especialistas, determinados fatores explicam o aumento, entre eles a crise econômica e a maior conscientização sobre transtornos como a ansiedade, auxiliando na busca do diagnóstico e tratamento $(5,14,15)$.

Em 1992, o relatório geral da ONU denominou o estresse como o mal do século. Esse estado de tensão, de fato, é cada vez mais comum em nossa era, especialmente nos exigentes e competitivos ambientes de trabalho. $O$ fenômeno de estresse nas instituições incide e coloca em situações de risco a motivação, o desempenho, a produtividade, a autoestima e a saúde de seus membros (16). Segundo Dejours, a erosão da vida mental ocorre na regulação da relação entre trabalhador e organização do trabalho (17). A Síndrome de Burnout - que é uma resposta ao estresse ocupacional crônico e afeta, principalmente, profissionais que se ocupam em prestar assistência às pessoas - vem ocorrendo com grande frequência, atualmente (14). É um processo em que há o esgotamento emocional e uma escassa realização pessoal, ocorrendo forte despersonalização, não resultando somente do estresse em si, mas do "estresse não mediado", não moderado, sem possibilidade de solução (18). O indivíduo nessa condição deixa de investir em seu trabalho e nas relações afetivas que dele decorrem, tornando-se incapaz de se envolver com ele (10). Segundo Dejours (19), o funcionamento mental poderia ser definido "como o modo pelo qual cada trabalhador ajusta as relações entre seu desejo e a realidade, entre seu passado, desde a infância, e seu presente, onde figura, entre outras coisas, o trabalho".

A literatura demonstra que as doenças mentais e comportamentais estão entre as doenças que mais afastam os trabalhadores da atividade laboral. A depressão é uma enfermidade pouco compreendida e cada vez mais tem mais casos diagnosticados. Estima-se que, nos dias atuais, 17 milhões de brasileiros sofram com esse problema, e, no que diz respeito ao ambiente de trabalho, somente no ano de $2016,37,8 \%$ de todas as licenças foram ocasionadas por quadros depressivos. Para os próximos anos, a expectativa não é otimista: 
segundo a Organização Mundial da Saúde, é possível que até 2020 ela se torne a principal doença incapacitante em todo o mundo (17).

Entre os servidores da UFSM estão incluídos os trabalhadores do Hospital Universitário de Santa Maria. A literatura revisada relata que os trabalhadores das áreas da saúde e, principalmente aqueles que atuam no ambiente hospitalar, apresentam maior nível de sofrimento e comprometimento físico e mental do seu estado geral de saúde, levando a se afastarem do trabalho por motivos de saúde mais frequentemente que os trabalhadores das outras áreas em geral $(19,20,21)$. Todos esses resultados explicitados e discutidos anteriormente estão em consonância e concordância maior ou menor com os dados encontrados nas referências pesquisadas e revisadas de estudos semelhantes (22). Braga et al (23) verificaram que $42,6 \%$ dos trabalhadores da Rede Básica de Saúde de Botucatu-SP apresentavam algum tipo de Transtorno Mental Comum (TMC). Schlindwein et al (24), em estudo com servidores públicos da Universidade Federal de Rondônia, encontraram que a média de idade geral dos servidores afastados é de 47,9 99,4 anos, semelhante à faixa etária dos servidores que mais se afastaram do trabalho durante o período de 2015 a 2017 na Universidade Federal de Santa Maria.

Dentre as doenças que têm forte associação com o trabalho, destacam-se os distúrbios osteomusculares relacionados ao trabalho (DORT), que agrupam diferentes doenças, em diversos segmentos corporais, e estão diretamente relacionadas ao movimento no trabalho, tendo em comum a expressão da dor, com intensidades variáveis. Os fatores psicossociais relacionados ao ambiente de trabalho exercem um papel adicional no desenvolvimento das DORT, com destaque para o trabalho monótono, controlado por pressões de produtividade e baixo apoio social. Os longos ciclos de trabalho, que demandavam uma variedade de movimentos, foram substituídos por máquinas em linhas de produção, manuseadas com ciclos mais curtos, porém com maior grau de tarefas e esforços repetitivos e monótonos (25).

As relações de trabalho, evidenciadas pela grande competitividade e pelos elevados níveis de exigência e produtividade são fatores que consequentemente promoveram alterações no processo saúde/doença de toda a humanidade (9). Os riscos de natureza ergonômica são gerados principalmente pela postura irregular que o trabalhador adota durante a jornada de trabalho, pois acaba assumindo posturas corporais não específicas para melhorar o desenvolvimento de sua atividade, devido à imposição de cargas físicas intensas ou a não observância de padrões ergonômicos nos postos de trabalho (26).

Segundo O'Neill (27), as LER/DORT podem corresponder entre $80 \%$ e $90 \%$ dos casos de doenças do trabalho registrados na Previdência Social nos últimos anos. A Fig. 3 demonstra que os servidores públicos federais mais acometidos por doenças incapacitantes para o trabalho na Universidade Federal de Santa Maria foram as mulheres, durante o período de 2015-2017, nas três principais classes de patologias prevalentes, transtornos mentais e comportamentais, doenças osteomusculares e do tecido conjuntivo e doenças do aparelho respiratório. As mulheres geralmente exercem atividades laborais consideradas secundárias e de baixa qualificação mas exigem atenção, concentração, detalhamento, agilidade, destreza, precisão, fineza, velocidade e repetitividade de movimentos, obediência, paciência, disciplina, responsabilidade, dedicação, delicadeza e sensibilidade (16). Dessa forma, especula-se que as prevalências de doenças osteomusculares são superiores nas mulheres devido às tarefas que elas desenvolvem e não necessariamente pela estrutura física. A maioria das mulheres atua em postos de trabalho expostos a ritmos extenuantes, associados ao trabalho realizado nas tarefas domésticas, representando esforço excessivo (28). Nesse sentindo, tem-se como exemplo a prática de atividade laboral no ambiente de trabalho, que tem se tornado um método preventivo eficaz no combate aos desconfortos e lesões aos quais os trabalhadores estão expostos em seus locais de trabalho e ainda ajudam a aliviar o estresse e ter um momento de descontração (6).

Schlindwein et al (24), em um estudo com servidores públicos da Universidade Federal de Rondônia, observaram que, no ano de 2011, foram concedidas 3.079 licenças saúde a servidores públicos federais. Desses afastamentos, 296 (9,6\%) foram motivados por transtornos mentais $e$ 
comportamentais; 70,6\% ocorreram em mulheres; e $29,4 \%$ ocorreram em sujeitos masculinos. Esses resultados corroboram os resultados encontrados para licenças de tratamento de saúde dos servidores da UFSM. Estudos epidemiológicos têm demonstrado diferenças de sexo na incidência, prevalência e curso de transtornos mentais e do comportamento. Na pesquisa realizada na Área de Captação do Hospital das Clínicas, da Faculdade de Medicina da USP, foram avaliados 1.464 indivíduos, uma amostra representativa da população geral domiciliada com idade igual ou superior a 18 anos. NesSe estudo, as mulheres apresentaram maior frequência de transtornos afetivos, transtornos ansiosos, transtornos dissociativos e transtornos alimentares. Os homens apresentaram maiores taxas de uso nocivo ou dependência de drogas, incluindo tabaco e álcool. Excluindo a dependência de tabaco, o risco de sofrer um transtorno mental durante a vida foi 1,5 vez maior para as mulheres que para os homens (29).

\section{CONSIDERAÇÕES FINAIS}

As informações encontradas neste estudo apontam para a necessidade urgente de planejamento, desenvolvimento e implementação da Política de Atenção à Saúde do Servidor (PASS) que deve ser organizada sob a forma do Subsistema de Atenção à Saúde do Servidor (SIASS), instituído pelo Decreto n. 0 6.833, de 29 de abril de 2009, que visa à manutenção da saúde do trabalhador, sua reabilitação e reintegração ao ambiente de trabalho, prevenindo, dessa forma, seu afastamento definitivo ou por longos períodos. Diante da realidade exposta por esses dados, acredita-se na importância e na necessidade de políticas, projetos e programas de promoção e prevenção em saúde, dedicadas aos servidores públicos federais. No caso da Universidade Federal de Santa Maria, há maior prevalência de transtornos mentais e comportamentais, doenças do aparelho respiratório e doenças do sistema osteomuscular e tecido conjuntivo, no sexo feminino e na faixa etária de 48 a 57 anos. A prevalência encontrada nesta investigação alerta para a magnitude do problema e a necessidade de melhores condições psicossociais no trabalho. Estes dados alertam para que medidas de promoção de saúde mental sejam melhoradas e efetivas no setor público federal.

\section{CONFLITO DE INTERESSES}

Não houve conflito de interesses na realização do estudo.

\section{FINANCIAMENTO}

O financiamento do estudo foi realizado pelo(s) pesquisador(es).

\section{REFERÊNCIAS BIBLIOGRÁFICAS}

1. Gasparini SM, Barreto SM, Assunção AA. O professor, as condições de trabalho e os efeitos sobre sua saúde. Educ. Pesq. 2005; 31(2): p189-199. 2. Alves M, Godoy SCB, Santana DM. Motivos de licenças médicas em um hospital de urgênciaemergência. Rev Bras Enferm. 2006; 59(2).

3. Araujo TM, Graça CC, Araujo E. Estresse ocupacional e saúde: contribuições do Modelo Demanda-Controle. Ciên Saúde Col. [Online]. 2003; 8(4): p.991-1003. http://dx.doi.org/10.1590/S1413 $-81232003000400021$.

4. Heloani JR, Capitão CG. Saúde Mental e Psicologia do Trabalho. Persp. 2003; 17 (2). http://dx.doi.org/10.1590/\$010288392003000200 011

5. Silva DMPP, Marziale MHP. Condições de trabalho versus absenteísmo doença no trabalho de enfermagem. Ciên Cuid Saúde. 2006; 5: p166172.

6. Santos GB, Melo FX. A importância da ginástica laboral no ambiente de trabalho. Rev Diál Interd. 2019; 9(4) [Acessado em: 22 set. 2019]. Disponível em: https://revistas.brazcubas.br/index.php/dialo gos/article/view/696/735.

7. Malhotra NK. Pesquisa de Marketing: uma orientação aplicada. SI: Bookman, 2012.

8. Brasil. Resolução no 466, de 12 de dezembro de 2012. Dispõe sobre diretrizes e normas regulamentadoras de pesquisas envolvendo seres humanos. Diário Ofic Rep Fed Brasil. Brasília, DF. [Online]; 13 jun. 2013. [Acesso em: 4 mar. 2020]. Disponível em: http://bit.ly/1mTMIS3.

9. Leite PC, Silva A, Merighi MAB. A mulher trabalhadora de enfermagem e os distúrbios osteomusculares relacionados ao trabalho. Rev Esc Enf. 2007; 41 (2): p287-291. 
10. Brasil. Ministério da Previdência e Assistência Social. Instrução normativa INSS/DC n. 98, de 5 de dezembro de 2003: aprova Norma Técnica sobre LER ou DORT. Brasília (DF). [Online] 2003. Disponível em: https://www.legisweb.com.b r/legislacao/?id=75579.

11. Bernardes J. Transtorno mental resulta em longos afastamentos do trabalho aponta estudo da FSP. [Acessado em 19 jun. 2018]. Disponível em: https://www5.usp.br/26411/transtorno-mentalresulta-em-longos-afastamentos-do-trabalho aponta-estudo-da-fsp/

12. Ribeiro HKP, Santos JDM, Silva MG, Medeiro FDA, Fernandes MA. Transtornos de ansiedade como causa de afastamentos laborais. Rev Bras Saúde Ocup. 2019; 44 [Acessado em 22 set. 2019]. Disponível em: http://www.scielo.br/pdf/rbso/v44 /2317-6369-rbso-44-e1.pdf http://dx.doi.org/10.1 590/2317-6369000021417

13. Baptista MC, Burton WN, Nahas AK, Wang YP, Viana MC, Andrade, LH. Absenteeism and Presenteeism Associated With Common Health Conditions in Brazilian Workers. J Occup Env Med. 2019; p303313.

https://doi.org/10.1097/JOM.0000000000001538 14. Codo W, Vasques-Menezes I. O que é burnout? Em W. Codo (Org.), Educação: Carinho e trabalho. 1999. pp. 237-255.

15. Alegretti L, Cancian N. Crise amplia casos de afastamento do trabalho por ansiedade. [Acessado em: 11 jun. 2018]. Disponível em: https://www1.folha.uol.com.br/mercado/2017/06 /1895999

16. Peres-Ramos J. Motivação no trabalho: abordagens teóricas. Psic. 1990; 1(2): p127-140.

17. Pedro J. Afastamento-de-profissionais-pordoencas-do-trabalho-cresce-25-no-Brasil/. http:// www.revistacobertura.com.br/2018/01/10/

18. Maslach C. Stress, burnout, and workaholism. In: Kilburg R, Nathan PE, Thoreson RW orgs. Professionals in distress: Issues, syndromes, and 77 solutions in psychology. Washington: American Psychological Association; 1994. p53-75.

19. Dejours C. A loucura do trabalho: estudo de psicopatologia do trabalho. 5ed. ampliada. São Paulo: Cortez-Oboré; 1992.

20. Montanholi LL, Tavares DMS, Oliveira GR. Estresse: fatores de risco no trabalho do enfermeiro hospitalar. Rev Bras Enferm. [Online].
2006; 59(5): p661-665. https://doi.org/10.1590/s0 034- 71672006000500013.

21. Nogueira CV, Maciel EC, Maciel RH, Aquino R. Afastamentos por transtornos mentais entre servidores públicos do estado do Ceará. 6 Congresso Nacional de Excelência em Gestão, Energia, Inovação, Tecnologia e Complexidade para a Gestão Sustentável 2010. Niterói (Brasil); 2010.

22. Gil AC. Como elaborar projetos de pesquisa. São Paulo: Atlas; 1991.

23. Braga LC, Carvalho LR, Binder MCP. Condições de trabalho e transtornos mentais comuns em trabalhadores da Rede Básica de Saúde de Botucatu-SP. Ciênc Saúde Colet. 2010; 15 (Supl. 1): p1585-1596.

24. Schlindwein VLDC, Moraes PM. Prevalência de transtornos mentais e comportamentais nas instituições públicas federais de Rondônia. Cad Psic Soc Trab. 2014; 17(1): p117-127. http://pepsic.bvsalud.org/pdf/cpst/v17n1/a09v17 n1.pdf.

25. Dosea GS, Oliveira CCC, Lima SO. Sintomatologia osteomuscular e qualidade de vida de portadores de distúrbios osteomusculares relacionados ao trabalho. Esc. Anna Nery [online]. Epub 28 nov. 2016; 20(4): e20160103 https://doi.org/10.5935/1414-8145.20160103.

26. Daer CRM, Ribeiro GCS. As alterações posturais e suas implicações na saúde do trabalhador. In: FERNANDES MG e col. Tópicos especiais em saúde do trabalhador e ergonomia. Recife: Fundação Antônio dos Santos Abreches; 2009. p97-105.

27. O'Neill MJ. LER/DORT: o desafio de vencer. São Paulo: Madras; 2003.

28. Alves EF. Perfil dos acidentes de trabalho no Brasil, 2004/2007. Saúde Pesq. 2010; 3(3): p297302.

29. Andrade L, Walters E, Gentil V, Laurenti R. Prevalence of ICD-10 mental disorders in a catchment area in the city of São Paulo, Brazil. Soc Psyc Psych Epidem. 2002; 37(7): p316-325. 


\title{
AGOSTINHO JOSÉ DE SOUZA LIMAEO ENSINO DA MEDICINA LEGAL
}

\author{
AGOSTINHO JOSÉ DE SOUZA LIMA AND THE TEACHING OF LEGAL MEDICINE
}

ARTIGO DE REVISÃO recebido em 30/11/2019, aceito em 20/12/2019

\author{
Daniel Turl Braga (1) \\ Currículo Lattes: 1742837075675279 - ID ORCID: 0000-0002-5062-6349 \\ Cristina Espindola Sedlmaier (1) \\ Currículo Lattes: 2809437491776188 - ID ORCID: 0000-0001-9862-6690 \\ Daniel Pinheiro Hernandez (2) \\ Currículo Lattes: 8009418572258052 - ID ORCID: 0000-0001-5173-2314
}

(1) Discente do curso de Medicina do Centro Universitário Serra dos Órgãos (UNIFESO) -

Teresópolis, Rio de Janeiro-RJ, Brasil.

(2) Orientador. Professor do Curso de Medicina e coordenador do Grupo de História da Medicina (GHM) do Centro Universitário Serra dos Órgãos (UNIFESO) - Teresópolis, Rio de Janeiro-RJ, Brasil.

e-mail: danielturl@hotmail.com

\section{RESUMO}

A Medicina Legal - e seu ensino no Brasil - constitui um capítulo peculiar na História da Medicina. Didaticamente, é dividida em: Primeira Fase (ou Fase Estrangeira); Segunda fase (Fase de transição), em que aconteceram as contribuições do médico Agostinho José de Souza Lima (1842-1921); e a Terceira fase (Fase de nacionalização), destacando Raimundo Nina Rodrigues. A Segunda Fase representou o início da "nacionalização" da Medicina Legal, quando o médico Souza Lima desempenhou papel fundamental. Objetivo: compreender o papel do médico Agostinho José de Souza Lima na construção da Medicina Legal brasileira. Métodos revisão bibliográfica em livros e artigos que versam sobre o tema. Resultados: em 1832, com a reforma do ensino superior no Brasil, a cadeira de Medicina Legal foi instituída nas Faculdades de Medicina. Porém, só em 1881, com Souza Lima, teve início o curso prático de tanatologia forense, nas dependências do necrotério da Corte. Esse período foi marcado por intensas discussões éticas sobre o ensino prático da perícia médica e o sigilo. Souza Lima teve papel de destaque no ensino da Medicina Legal, no seu conteúdo prático, desenvolvimento laboratorial, publicações científicas, comentários sobre as leis civis e penais do Brasil e no estudo da toxicologia. Conclusão: as ações de Souza Lima possibilitaram a estruturação da Medicina Legal como disciplina, dentro das Faculdades de Medicina brasileiras, sendo referência da Medicina Forense no Brasil. Seus grandes feitos se traduzem em incentivo aos mais novos, estudantes e médicos brasileiros. Palavras-chave: medicina legal, tanatologia, história da medicina. 


\section{ABSTRACT}

Legal Medicine and it's teaching at Brasil constitute a peculiar chapter in Medical History. Didactically divided in: First fase (or Foreign fase) until 1877; Second fase (or Transitional fase), period in which Doctor Agostinho José de Souza Lima (1842-1921) made his contributions; and the Third fase (Nationalization fase) when Raimundo Nina Rodrigues was prominent. The Second fase represented the first step towards the "nationalization" of Forensic Medicine, when doctor Agostinho José de Souza Lima played a fundamental role. Objective: To understand the role of Doctor Agostinho José de Souza Lima on the constitution of Brazilian Legal Medicine. Method: bibliographical review of books and articles about the theme. Discussion: in 1832, with the reform of higher education in Brazil, the chair of Forensic Medicine was established in medical universities. However, it was not until 1881, with Souza Lima, that the practical teaching of forensic thanatology began in the Court's morgue. This period was marked by intense ethical discussions about the practical teaching of medical expertise and confidentiality. Souza Lima had a prominent role in the teaching of Legal Medicine, its practical teaching, laboratory development, scientific publications, comments on Brazilian civil and criminal laws and the study of toxicology. Conclusion: Souza Lima's actions enabled the structuring of forensic medicine as a discipline within Brazilian medical colleges, becoming a reference for Legal Medicine in Brazil. His great achievements translate into encouragement to the youngest, students and Brazilian doctors.

Keywords: forensic medicine, thanatology, history of medicine.

\section{INTRODUÇÃO}

O estudo da História da Medicina possibilita, ao médico e ao graduando, a construção de um pensamento crítico e olhar humanístico, necessários para uma formação integral deles, sendo uma das disciplinas - somada à Filosofia e a Ética - primordiais para instrumentalizá-los ao desenvolvimento do pensamento médico (1-6). Gusmão refere que, ao estudar a história da sua profissão, o médico tem seus pensamentos, bem como suas ações, influenciados de forma positiva, frisando que "(...) a importância da História da Medicina é afirmar a importância da própria medicina". (1, p151)

Trazendo esse entendimento para o estudo da Medicina Legal, quando se pretende compreender essa ciência e seu exercício, é imperativo conhecer seu percurso dentro da História. Nesse sentido, o exercício da Medicina Legal é marcado por necessidades de ordem pública e social, tendo importante papel nos relacionamentos sociais e políticos de cada época, trazendo o equilíbrio social (7). Entender as ordens vigentes emum período, os pensamentos e leis que determinavam as relações humanas, é papel da História da Medicina. $(7,8)$ Assim, didaticamente, o médico Dr. Flamínio Fávero - discípulo do Dr. Oscar Freire de Carvalho e formado na primeira turma da Faculdade de Medicina e Cirurgia de São Paulo, em 1919, em cuja tese Evolução Scientifica da Medicina Legal no Brasil, escrita em 1922 - dividiu o período da história da Medicina Legal no Brasil em três fases, cada qual contendo a influência de importantes figuras públicas e científicas da época. (9-11)

No Brasil, as faculdades de Medicina foram criadas com a chegada da família real, por D. João VI. Em 1808, na Bahia, foi lavrado o ato que criou a Escola Anatômica e Cirúrgica, que se destinava, em um período de quatro anos, a formar cirurgiões e médicos práticos. E, em 1809, no Rio de Janeiro, foi criada outra escola médica, mantendo os mesmos padrões da primeira. Apenas em 1832 essas escolas foram denominadas Faculdades de Medicina, com duração de seis anos e em uma conformação parecida com as faculdades da França e demais países europeus. $(12,13)$

A primeira fase, denominada Fase estrangeira, durou até 1877 . Nesse período, a disciplina era fruto de modelos estrangeiros, tendo as faculdades de medicina do país utilizado a mesma literatura, mas não era observada a originalidade nos estudos dos estudantes da época. Vale destacar que, nessa época, não havia a rotina da observação dos fatos 
e verificações pessoais sobre o conteúdo. Além disso, os estudos estrangeiros não eram adaptados às condições judiciárias do país. $(8,10)$

Uma referência tida como obrigatória, nas faculdades de Medicina do Brasil, era o Précis de Medecine Légale, escrito pelo francês Dr. Charles Vibert. Essa obra era frequentemente consultada pelos estudantes e professores, e não havia debates e divergências de pensamentos, visto que a medicina legal, naquele período, circulava como um verdadeiro lugar comum, ditada, principalmente, pela literatura francesa. $(8,9)$

Durante essa fase, Francisco Ferreira de Abreu (barão de Teresópolis), Lente Catedrático da disciplina na Faculdade de Medicina do Rio de Janeiro, apresentou estudos sobre toxicologia, com interpretações clínicas de envenenamentos. Muito embora essas pesquisas tenham se iniciado na Fase Estrangeira, dando ao barão de Teresópolis uma personalidade ímpar, ele foi considerado uma exceção no período. $(8,9,14)$

Já a Segunda fase da Medicina Legal brasileira, chamada de Fase de transição, teve seu início com o Doutor Agostinho José de Souza Lima, logo após ser nomeado Lente Catedrático de Medicina Legal na Faculdade de Medicina do Rio de Janeiro. Além da importante participação política e pública, por meio de comentários às leis cíveis e penais da época, também foi responsável pela criação do primeiro curso prático de Tanatologia no necrotério da Corte e pelo desenvolvimento laboratorial atrelado a ela. (7-9)

O médico Souza Lima foi autor de importantes publicações, tidas como referências em Faculdades de Medicina e Direito do território brasileiro. Dentre suas obras, destacam-se o Tratado de Medicina Legal e o Tratado de Toxicologia. De acordo com Dr. Flamínio Fávero, a obra de Souza Lima não teve maior destaque porque seus comentários às leis brasileiras estariam consonantes com a literatura estrangeira, não lhe dando o caráter original. Contudo, foi um importante e necessário momento de transição dentro da construção da Medicina Legal. (7-10)

A Fase da nacionalização, terceira grande etapa mencionada pelo Dr. Flamínio Fávero, ocorreu no início do século 20, tendo como extraordinário integrante o Dr. Nina Rodrigues, também conhecido como o verdadeiro espírito da originalidade da
Medicina Legal brasileira, além de elevá-la à especialidade e disciplina científica. Seu destaque e contribuições foram galgados pelo entendimento da disciplina, utilizando as leis brasileiras. $(10,13,15-$ 17)

Focando na Segunda fase, uma vez que aquele período de transição foi extremamente importante e necessário para que a Medicina Forense brasileira cunhasse sua personalidade, objetivou-se compreender o papel do médico Agostinho José de Souza Lima na construção da Medicina Legal no Brasil. Inspirados nas palavras de Almeida (18, p375), que dizia que: “(...) O culto aos grandes vultos do passado não apenas enobrece como representa a melhor forma de incentivo aos novos (...)", escolhemos o Dr. Agostinho como objeto de estudo.

Na região serrana do Rio de Janeiro, na cidade de Teresópolis, está sediado o Centro Universitário Serra dos Órgãos (Unifeso). E, nesse local, encontrase o Grupo de História da Medicina (GHM), uma atividade de extensão que reúne acadêmicos de medicina, do primeiro ao décimo segundo períodos, que partilham do mesmo interesse pelo tema História da Medicina. Os alunos participantes produzem trabalhos referentes a essa temática, principalmente da especialidade que almejam, com apresentações e discussões semanais. Tal atividade permite aproximar os acadêmicos de sua própria história e das Humanidades Médicas, imprescindíveis ao médico, em qualquer tempo da História Humana.

Por meio da discussão sobre as especialidades desejadas, nasceu o interesse em conhecer sobre a história da Medicina Legal.

\section{MATERIAL E MÉTODO}

Uma pesquisa bibliográfica foi realizada nas bases de dados Scielo e Lilacs, a partir dos descritores: História da Medicina e Medicina Legal. Foram encontrados 222 artigos versando sobre a história da Medicina Legal. Os critérios de inclusão foram textos completos e redigidos em português, inglês ou espanhol. Fez-se uma cuidadosa leitura, objetivando encontrar textos específicos sobre a história da Medicina Legal brasileira na Fase de transição. Depois, fez-se a leitura de caráter exploratório, verificando se os critérios de inclusão 
foram abrangidos. Posteriormente, foram feitos o fichamento e a leitura analítica e a descrição dos achados. A definição dos artigos escolhidos se concentrou nos que traziam, à luz, o papel do médico Agostinho José de Souza Lima na Medicina Legal brasileira.

Não há conflitos de interesse.

\section{DISCUSSÃO}

Filho do coronel Severo José de Souza Lima e de Nympha Symphronia de Araújo Lima, Agostinho José de Souza Lima nasceu na cidade de Cuiabá, Mato Grosso, em 11 de março de 1842 e, aos sete anos, em 1849, chegou à cidade de Niterói, no Rio de Janeiro. Vivendo nessa cidade, o menino Souza Lima fez seus estudos no Colégio Dom Pedro II, destacando-se dentre os melhores alunos da sala. $(12,15,16,19,20)$

O ano de 1849 foi de extrema importância, pois foi o momento em que se evidenciou, no mês de dezembro daquele ano, a primeira notícia sobre casos de febre amarela no Rio de Janeiro, cidade vizinha a Niterói. Dentro deste contexto, as discussões sobre o fim do tráfico intercontinental de escravos se acaloravam. $(21,22)$

Em 1857, seu pai faleceu e, dois anos depois, ingressou na Faculdade de Medicina do Rio de Janeiro. É importante ressaltar que o falecimento de seu genitor foi um dos grandes motivadores para a escolha na Medicina. Depois de cinco anos de estudos, recebeu o grau de doutor com a tese Qual a natureza e o tratamento das urinas vulgarmente chamadas leitosas ou quilúria? e, um ano após ter completado a graduação - em 1865 -, casou-se com a sua prima, Izabel Augusta da Silva Campos. $(23,24)$ Um importante fato histórico da época foi a guerra do Paraguai (1864-1870), onde o Rio de Janeiro se encontrava em um momento de preparação militar para o conflito. Realengo, bairro da cidade, tornouse zona militar, com a instalação de uma Escola de Tiro e da Academia Imperial Militar. O Dr. Souza Lima, além de médico da Escola de Tiro, foi nomeado Tenente Cirurgião do Sétimo Batalhão da Guarda Nacional, exercendo a função de CirurgiãoMor. $(23,25)$

Tornou-se docente da Seção de Ciências Acessórias da Faculdade de Medicina do Rio de Janeiro, em 1871, e passou a presidir a Comissão Sanitária da
Freguesia de São José. O Rio de Janeiro, nessa época, passava por epidemias de febre amarela e, para conter a disseminação da doença, estavam sendo executados projetos para transformações, como a construção de três capelas em três grandes cemitérios da cidade, com o intuito de velar os mortos em um ambiente mais adequado. Anterior a esse período, o velamento se dava nas igrejas. (24-26)

Foi nomeado membro da Junta Central de Higiene Pública do Rio de Janeiro, em 1876. Esse período foi marcado por graves problemas estruturais e de saneamento básico no Rio de Janeiro, repercutindo na forma de diversas doenças infectocontagiosas, sendo um importante desafio para a Saúde Pública da época. (25)

O processo de transição da Medicina Legal ocorreu após a nomeação do Dr. Souza Lima como Lente Catedrático de Medicina Legal na Faculdade do Rio de Janeiro, em 1877. Nesse mesmo ano, Agostinho sofreu um acidente vascular cerebral (AVC). Em 1879, foi nomeado membro titular da Academia Imperial de Medicina, com sua tese Da cremação dos cadáveres e, no mesmo ano, iniciou seu curso prático de Tanatologia Forense no necrotério oficial da Corte. (23-27)

Souza Lima também assumiu a presidência da Academia Imperial de Medicina, de 1883 a 1889, e da Academia Nacional de Medicina, de 1890 a 1891, onde teve importante participação e voz nas reuniões anuais que se realizavam. $(23,25)$

Nesse momento histórico de grandes mudanças, o Dr. Agostinho favoreceu, também, importantes modificações dentro da Medicina Legal. Para ele, a perícia médica era "toda a sindicância promovida por autoridade policial ou judiciária, acompanhada de exame que, pela natureza do mesmo, os peritos são ou devem ser médicos". $(28$, p39)

E foi com esse entendimento que, em 1883, propôs modificações do Código Penal sobre o infanticídio. Isso se deu porque, de acordo com a lei de 1830 , o crime para quem o praticasse seria de três a 12 anos de prisão. Comparando ao homicídio em adultos, neste recebia, como pena, de seis a 24 anos de prisão. Assim, após a Proclamação da República, com a formulação de um novo Código Penal, a proposta foi inserida. $(9,10,15,17,19,21,26,27)$

Em 1886, Dr. Agostinho, durante as sessões anuais da Academia Imperial de Medicina, discursou sobre 
as medidas de profilaxia ao suicídio. Isso porque, naquele ano, ocorreu um aumento no número de suicídios na cidade, sendo tema frequentemente abordado em jornais e noticiários da cidade. Souza Lima se interessou pelo assunto, procurando estudos baseados na literatura estrangeira, e concluiu que o suicídio é um infortúnio de caráter contagioso, que se propagava através da influência e imitação. Então, durante a reunião, na qual se encontrava presente Dom Pedro II e importantes figuras públicas, propôs, como intervenção a esse cenário, o envio de cartas para toda a imprensa da cidade. Nelas constariam orientações quanto à proibição de notícias sobre o assunto suicídio, figurando como fator profilático contra o ato por imitação. $(17,19,21,25-27)$

Agostinho publicou, em 1890, seu primeiro Tratado de Toxicologia e, em 1891, conseguiu que a disciplina configurasse como obrigatória nos cursos de Direito no Brasil. Em 1892, passou a ocupar a cadeira de Medicina Legal na Faculdade Livre de Sciencias Jurídicas e Sociaes (atual Faculdade de Direito da Universidade Federal do Rio de Janeiro). Nesse mesmo ano, discutiu sobre a importância na profilaxia da tuberculose, durante a reunião anual da Academia Nacional de Medicina. Tal doença era bastante comum na população que habitava os cortiços na cidade do Rio de Janeiro, já que nessas instalações não havia circulação de ar adequada e necessária frente à excessiva concentração de pessoas que ali viviam. $(19,21,25-27)$

Já em 1893, publicou o Manual de Química Legal e, dois anos mais tarde, editou seu primeiro Tratado de Medicina Legal, que se tornou importante literatura da época, com diversas edições. Reassumiu, por um ano, a presidência da Academia Nacional de Medicina, em 1896 e, em 1909, recebeu o título de membro honorário da Academia Nacional de Medicina. $(17,19,21,23,25)$

No ano de 1913, o médico Souza Lima produziu importante crítica aos procedimentos usuais de diagnóstico de morte. Durante seu relatório, enviado por meio de cartas a diversas autoridades à época, ele fez menção à forma inadequada como ocorria a emissão dos Atestados de Óbitos que, muitas vezes, eram dados sem a devida constatação do falecimento. Em uma de suas cartas, discorreu sobre a sua vivência como médico legista, citando, como um curioso fato, o caso da nora do marquês de Sapucaí, que vivia nas redondezas de Teresópolis - cidade localizada na região serrana do Estado do Rio de Janeiro. A mulher, vítima de grave infecção puerperal, entrou em profunda letargia, e estado de morte aparente, por cerca de trinta horas. Nesse espaço de tempo, a puérpera manteve sua audição preservada, tendo a chance de ouvir que não fora sepultada devido ao fato de o caixão, encomendado pela Corte, não ter chegado a tempo. Após notarem que ela estava viva, foi reanimada e viveu por mais 33 anos. $(21,23,25-28)$

Vindo para o campo da docência, com constante ascendência, amparada pela Lei Maximiliano (decreto 11.530, de 18 de março de 1915), trouxe a permissão do acesso, de professores e alunos, ao Serviço Médico-Legal, bem como a validade jurídica dos relatórios por eles elaborados. (8)

Após muitos e importantes anos militando na Medicina Legal, Dr. Agostinho José de Souza Lima faleceu em 28 de dezembro de 1921, na cidade de Petrópolis. E, em 1963, durante uma sessão ocorrida em 3 de outubro na Academia Nacional de Medicina, foi escolhido como Patrono da Cadeira número 3. (23)

\section{CONCLUSÃO}

O estudo da História da Medicina nos traz à luz grandes vultos e ações determinantes para cunhar a Medicina como a conhecemos atualmente. Dentro desse grande tema, a História da Medicina Legal nos mostra importantes trabalhos e ações que trouxeram a valorosa notoriedade que, por mérito, tem.

Dito isso, estudar as ações de Souza Lima permitem concluir que possibilitaram a estruturação da Medicina Legal como disciplina, dentro das Faculdades de Medicina brasileiras. Além disso, foi um importante momento de transição para a nacionalização da disciplina no território, sendo a ponte necessária para chegar à Terceira fase. Devido aos seus grande feitos, transformou-se em referência da Medicina Forense no Brasil.

\section{REFERÊNCIAS BIBLIOGRÁFICAS}

1. Gusmão S. História da Medicina. Evolução e Importância. Rev Med Minas Gerais. 2003; 13(2), p146-52.2. Chaple ERB. La docencia de la historia de la Medicina en Cuba. Educación Médica Superior. 
2014; 28(2): p216-228.

3. Hernandez DP. A relevância da História da Medicina na formação integral do graduando. Jornal Brasileiro de História da Medicina. out./nov./dez. 2017; v. 17, n 1, p58-60. Disponível em: https://docs.wixstatic.com/ugd/be8daf_a53f872bc 33e45a4bf3b7ad74e35d749.pdf. Acesso em: 22 jul. 2019.

4. Lacaz CS. Temas de Medicina. Biografias, Doenças e Problemas Sociais. São Paulo: Lemos Editorial; 1997.

5. Ivamoto HS. Lacaz, Ciência e Humanismo na Casa de Arnaldo. São Paulo: Lemos Editorial; 2003.

6. Oliveira $A B$. A evolução da medicina: até o início do século XX. São Paulo: Pioneira, Secretaria de Estado de Cultura; 1981.

7. França GV. A Medicina Legal como norteadora na busca da verdade real. Disponível em: http://www.anml.org.br/wp-content/uploads/2016 /12/Art-A-Medicina-Legal-como-norteadora.pdf. Acesso em: 22 jul. 2019.

8. Prestes Junior LCL, Moraes TM, Rangel M. A Importância do Ensino da Medicina Legal na Formação da Carreira Jurídica. EMERJ. jul.-set. 2012; 15(59): p76-84.

9. Alvarez MC, Salla F, Alves K. Medicina legal, criminologia e punição: aspectos da trajetória intelectual e profissional de Flamínio Fávero (18951982). Saúde Ética Just. 2012; 17(2), p57-65. https://doi.org/10.11606/issn.23172770.v17i2p57-65

10. Miziara ID, Miziara CSMG, Muñoz DR. A institucionalização da Medicina Legal no Brasil. Saúde Ética Just. 2012;17(2): p66-74.

11. Academia de Medicina de São Paulo. Flamínio Fávero. Biografias. Disponível em https://www.academiamedicinasaopaulo.org.br/b iografias/148/BIOGRAFIA-FLAMINIO-FAVERO.pdf. Acesso em: 21 jul 2019.

12. Meira C. A importância do ensino da Medicina Legal. Saúde, Ética \& Justiça. 1996; 1(1): p76-87.

13. Alves RH. Medicina Legal entre Direito ou Medicina: o caminho de sua institucionalização no Brasil. 2014. 107 f. Tese (Doutorado em História da Ciência) - Pontifícia Universidade Católica de São Paulo, São Paulo, 2014.

14. Academia Brasileira de Letras. Francisco Ferreira de Abreu (Barão de Teresópolis). Biografia. Disponível em http://www.anm.org.br/conteudo_ view. asp ?id $=338 \&$ descricao $=$ Francisco + Ferreira + de +Abreu. Acesso em: 21 jul 2019.

15. Fernandes CR, Guimarães MA, Mata KM, Frajacomo FTT, Demarzo MMP, Garcia SB. A história da Medicina Forense. Brazilian Journal of Forensic Sciences, Medical Law and Bioethics. 2011; 1(1): p1-7. http://dx.doi.org/10.17063/bjfs1-1-20111

16. Maio MC. Brazilian Physician Nina Rodrigues: Analysis of a Scientic Career. Cad. Saúde Públ., Rio de Janeiro, 11 (2): p226-237, Apr/Jun, 1995.

17. Muakad I. A Medicina Legal: evolução e sua importância para os operadores do Direito. São Paulo: Universidade Presbiteriana Mackenzie. 2013. Disponível em https://ronaldogalvao.com.br/wpcontent/uploads/2014/02/artigolrene_13_03.pdf. Acesso em: 21 jul 2019.

18. Almeida MO. A propósito do jubileu de Miguel Couto. Revista Brasileira De Medicina [Rev Bras Med], 1954 May; Vol. 11 (5), p375-7.

19. Cerqueira E. A perícia médico-legal e o ensino: dissidências e discussões na Sociedade Brasileira de Neurologia, Psiquiatria e Medicina Legal. História, Ciências, Saúde - Manguinhos. 2015; v.22, n.2, abr.-jun. p641-649.

20. Silva NV. Agostinho José de Souza Lima. Médicos que atuaram no Hospital Nacional de Alienados (blog). In: Biblioteca Virtual em História do Patrimônio Cultural da Saúde, 2019. Disponível em http://hpcs.bvsalud.org/wp-content/uploads/2019 /09/Lima-Souza-perfeito-2.pdf. Acessado em 22 jul 2019.

21. Kodama K. Os debates pelo fim do tráfico no periódico O Philantropo (1849-1852) e a formação do povo: doenças, raça e escravidão. Rev. Bras. Hist., São Paulo, v. 28, n. 56, p407-430, 2008. Disponível em http://www.scielo.br/scielo.php? script=sci_arttext \&pid=S0102-01882008000200007 \&lng=en\&nrm=iso. Acessado em 22 jul 2019. http://dx.doi.org/10.1590/\$0102-01882008000200 007.

22. Tasco AH. O Surto de Febre Amarela no Rio de Janeiro (1928-1929) (Pontos Controversos). Net. 2018. Disponível em http://www.13snhct.sbhc.org .br/resources/anais/10/1345081434_ARQUIVO_Su rtodefebeamarelanoRiodeJaneiro.pdf. Acessado em 22 jul 2019.

23. Academia Nacional de Medicina. Agostinho José de Souza Lima (Cadeira No. 03). Disponível em < http://www.anm.org.br/conteudo_view.asp?ld= 
130>. Acessado em 23 jul 2019.

24. Mota CG. História de um silêncio: a guerra contra o Paraguai (1864-1870) 130 anos depois. Estud. av., São Paulo, v 9, n 24, p243-254, Aug. 1995. Disponível em http://www.scielo.br/ scielo.php?Script=sci_arttext\&pid=S010340141995000200012\&lng=en\&nrm= iso. Acessado em 22 jul 2019. http://dx.doi.org/10 .1590/S0103-40141995000200012

25. Hirata A. Souza Lima: o primaz da medicina legal no país. (Notáveis do Direito). Jornal Carta Forense. Disponível em http://www.cartaforense.com.br/co nteudo/colunas/souza-lima-o-primaz-da-medicinalegal-no-pais/18250. Acessado em 22 jul 2019.

26. Antunes JLF. Medicina, leis e moral: pensamento médico e comportamento no Brasil (1870-1930). São Paulo: Editora Unesp,1999.

27. Antunes JLF. Crime, sexo, morte. Avatares da Medicina no Brasil. Tese de Doutorado em Sociologia apresentada ao Departamento de Sociologia da Faculdade de Filosofia, Letras e Ciências Humanas da Universidade de São Paulo. São Paulo, 1995.

28. Costa Júnior JBO. Os primórdios da perícia médica. Revista Da Faculdade De Direito, Universidade De São Paulo, 1982; 77, p39-52. Disponível em http://www.revistas.usp.br/rfdusp/ article/view/66940. Acessado em 23 jul 2019. 


\section{VIRTÓPSIA: AVANÇOS TECNOLÓGICOS EM MEDICINA LEGAL E PERICIA MÉDICA VIRTÓPSIA: TECHNOLOGICAL ADVANCES IN LEGAL MEDICINE AND MEDICAL EXPERTISE}

ARTIGO ORIGINAL recebido 25/02/2020, aceito em 29/02/2020

\section{Nilton Tellian ${ }^{(1)}$ \\ Currículo Lattes: 6818373950676124}

(1) Pós-graduando em Medicina Legal e Perícias Médicas, Faculdade de Medicina da Universidade de São Paulo, São Paulo-SP, Brasil.

e-mail: niltontellian@globo.com

\section{RESUMO}

Nas últimas décadas, houve um importante avanço na medicina forense, como o surgimento da virtópsia, técnica radiológica forense que utiliza imagens radiológicas em três dimensões, seja pela TC ou pela RM, e tem contribuído muito para a ciência forense. Apesar de não ser possível observar a tonalidade e a consistência das estruturas como ocorre na autópsia convencional, esses métodos obtêm imagens post-mortem em alta resolução auxiliando as autópsias convencionais. A TC é um método de imagem que permite a identificação de traumas, fraturas e calcificações e a RM é útil para o estudo de tecidos moles, porém, não diferencia as colorações das lesões, mas a natureza delas. Observa-se que a virtópsia vem se mostrando um método superior e complementar em relação aos métodos tradicionais de autópsia e tem muitas vantagens, no entanto, ainda são necessários estudos para substituir por completo a autópsia convencional por exames de imagens.

Palavras-chave: ciência forense, radiologia forense, autópsia, autópsia digital, virtópsia, medicina legal, perícias médicas.

\section{ABSTRACT}

In recent decades there has been an important advance in forensic medicine as the emergence of virtopsy, a technique in forensic radiology which uses radiological images in three dimensions, either by CT or MRI, exams which have contributed to the diagnosis of various diseases. Although it is not possible to observe the color tone and consistency of structures as in conventional autopsy, these methods obtain postmortem images through virtopsy, with high resolution images which aid conventional autopsy. The objective of this study is to conduct a literature review on virtopsy and analyze the advantages and disadvantages of CT and MRI usage. $\mathrm{CT}$ is an imaging method that allows the identification of trauma, fractures and calcifications and MRI is useful for the study of soft tissue, however not differentiating the colorations of injuries but the nature of them. It is observed that the virtopsy has proven to be a superior and complementary method compared to traditional methods of autopsy and has many advantages. However, further studies are needed to completely replace conventional autopsy with imaging tests.

Keywords: forensic science, forensic radiology, autopsy, digital autopsy, virtopsia, legal Medicine. 


\section{INTRODUÇÃO}

$\mathrm{Na}$ Antiguidade, já se fazia presente a Medicina Legal, até então uma arte, como a própria Medicina. $\mathrm{Na}$ Roma antiga, o corpo de César, após seu assassinato, foi submetido a exame tanatológico pelo médico Antístio, que declarou que apenas um dos ferimentos fora efetivamente o causador da morte. Esse exame, entretanto, ainda era superficial, posto que a necropsia se constituía em violação ao cadáver. (1)

Durante a Idade Média, ressalta-se o período Carolíngio, em que diversos exames eram referidos na legislação, desde os que determinavam os ferimentos em batalha, até os julgamentos eram submetidos ao crivo médico - prática suprimida com a adoção do direito germânico. (1)

Na Baixa Idade Média e Renascença, com a intervenção do Direito Canônico, a prova médica retomou paulatinamente sua importância. É na Alemanha que se encontra seu verdadeiro berço, com a Constituição do Império Germânico, que tornava obrigatória a perícia em casos como lesões corporais, homicídios, abortos e outros. (1)

Considera-se que o período moderno, propriamente científico da Medicina Legal, dá-se a partir de 1602, com a publicação na Itália da obra de Fortunato Fidelis, à qual se seguiram estudos sobre esse ramo da Medicina a serviço do Direito.

(1)

No século 19, a ciência ganhou finalmente os foros de autonomia, e sua conceituação básica, evoluindo concomitantemente aos expressivos progressos do conhecimento humano, a invenção de novos aparelhos e descobertas de novas técnicas e padrões, cada vez mais precisos e fiéis. (1)

A Medicina Legal e Perícia Médica é uma especialidade médica que engloba todas as outras especialidades, sendo a justiça social seu principal objetivo. É notório que a medicina e suas respectivas tecnologias contribuem diretamente para a qualidade do trabalho pericial, mesmo o perito médico não atuando diretamente com a vida e com a saúde, mas com evidências fundamentais em busca da verdade dos fatos. (2)

A perícia médica, há muito tempo, vem sendo utilizada para apoiar as investigações a cargo das polícias técnicas, sempre que do evento investigado resulte em dano físico e/ou mental. O trabalho médico-pericial também tem sido requisitado pelos juízes, objetivando definir existência, grau, natureza e causa de lesões físicas ou mentais sofridas por pessoas que recorrem ao Poder Judiciário, na expectativa da reparação de danos sofridos sob a responsabilidade direta ou indireta de terceiros. (2) As perícias médicas realizadas nos Institutos Médico Legais podem incluir, por exemplo, o estudo de causa mortis, situações de violência (colheita de vestígios; diagnóstico diferencial entre uma etiologia criminosa, acidental ou natural; definição das consequências temporárias e permanentes para a vítima de um traumatismo), a avaliação do estado de toxicodependência, a determinação do gênero, a identificação de corpos ou restos cadavéricos, a determinação da imputabilidade, o estudo da filiação, a pesquisa de drogas de abuso ou outros tóxicos em amostras biológicas, entre outros (2).

A palavra autópsia, derivada do grego antigo

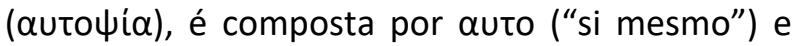
o廿ía ("visão"), significando "ver por si próprio" (3). Além de permitir o estudo dos processos tanatológicos com a identificação de cadáveres e os estudos antropológicos, a autópsia tem o objetivo de desvendar a causa de morte e as circunstâncias em que ocorreram, proporcionando-nos também a investigação de processos patológicos e seus efeitos orgânicos. (3)

O conceito e a prática da autópsia são também a controvérsia que a rodeia, envolvendo problemas éticos, sociais, religiosos e emocionais. (3)

A utilização da tecnologia na ciência forense possibilita vantagens quanto à análise mais detalhada de fraturas, patologias específicas, reações vitais, reconstrução de lesões, coleções aéreas provenientes de eventos embólicos, enfisema subcutâneo de natureza traumática, entre muitas outras utilizações. (4)

Inúmeras são as aplicações da radiologia forense, como na determinação da idade e nos casos de infanticídio pela docimasia radiológica de bordas, na qual os pulmões que não expandiram mostrarse-ão opacos aos raios $X$, não sendo visualizados o diafragma e as bordas cardíacas. (4)

A virtópsia, ou autópsia virtual, contribuiu na última década com substanciais avanços na área da medicina forense. Aplica-se a tecnologia radiológica, como Tomografia Computadorizada post mortem (TC-PM), a Ressonância Magnética 
post mortem (RM-PM), a Angiotomografia Computadoerizada post-mortem (AngioTC-PM) e a Angioressonância Magnética post mortem (AngioRM-PM), com o objetivo de auxiliar as técnicas necroscópicas, um conjunto de dados que, processados e reunidos, nos permitem obter informações valiosas que colaboram no processo técnico necroscópico. (4)

Um dos mais brilhantes avanços da medicina foi o surgimento de técnicas de imagens como a Tomografia Computadorizada (TC) e a Ressonância Magnética (RM). Essas técnicas têm sido utilizadas com maior frequência nos procedimentos necropsiais. (5)

Utilizando a TC, é possível obter imagens digitais com secção transversal a partir de projeções radiográficas transaxiais e reconstrução em 2D e 3D por meio da TC helicoidal. (5)

Portanto, a radiologia aplicada à Medicina Legal e Perícia Médica, principalmente nos procedimentos necroscópicos, vem colaborando para elucidar patologias, eventos traumáticos, assim como detalhar tridimensionalmente os efeitos balísticos nas vítimas de disparos por armas de fogo. (5)

\subsection{OBJETIVOS}

O principal objetivo deste estudo foi realizar uma revisão da literatura existente sobre os avanços e as inovações da tecnologia empregados na Medicina Legal e Perícia Médica, principalmente sua utilização nas áreas da ciência forense. Abordamos questões referentes às técnicas radiológicas forenses e autópsia virtual; a análise das novas técnicas forense e a utilização nas autópsias convencionais e nas perícias médicas.

\section{MATERIAL E MÉTOdO}

Fez-se uma revisão bibliográfica acerca do tema proposto. Os critérios de inclusão foram os artigos disponibilizados gratuitamente na íntegra, publicados entre os anos de 2000 e 2019 . Foram excluídos os que apresentavam idioma diferente do português ou inglês. As bases de dados utilizadas foram Scielo, Medline, Pubmed, Lilacs e biblioteca digital; os descritores, combinados entre si ou não, foram: ciência forense, radiologia forense, autópsia, autópsia digital, virtópsia, medicina legal, perícias médicas.

\section{DESENVOLVIMENTO}

Nos últimos anos, as inovações e os avanços tecnológicos influenciam uma nova era na ciência forense, principalmente por meio das técnicas de imagens radiológicas. Novos procedimentos alternativos à autópsia tradicional vêm sendo cada vez mais utilizados, como ultrassom pós-morte, endoscopia cadavérica, tomografia computadorizada e ressonância magnética. (6)

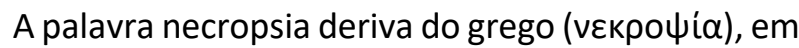

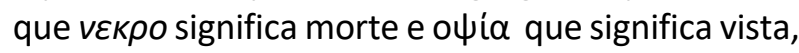
ou seja, é um exame realizado após a morte de um indivíduo. O termo autópsia é um sinônimo de necropsia, e significa ver por si mesmo, ou seja, ver um semelhante ali na frente sendo examinado, é derivada das palavra grega ( $\alpha$ uto $\psi i \alpha)$ ). (6)

A necropsia é a técnica utilizada para descobrir a causa morte, podendo ter origem de causas naturais, doenças, violência ou suspeita de violência, quer seja para esclarecer práticas criminosas ou diagnósticos clínicos. (6)

Um projeto de pesquisa conhecido como "Projeto Virtopsy", iniciado no século 20 pelo Prof. Richard Dirnhofer, solucionou um homicídio na Suíça através do escaneamento o crânio da vítima, já que naquela época a arma do crime permanecia um mistério. Podemos dizer que foi a partir daí que o termo "virtópsia" tomou forma, gerando um neologismo, combinando "virtual" e "autópsia". Essa técnica propõe substituir a necropsia com a abertura de cadáver, conhecida também como necropsia tradicional, por um sistema virtual, ou seja, a elaboração de um mapa interno do cadáver por meio da imagem. (6)

A virtópsia consiste em um conjunto de técnicas de diagnóstico médico. Pode ser descrita como uma ciência e uma arte. Ciência porque organiza suas técnicas e procedimentos com intuito determinado, solicitando assim maior conhecimento, obtido por observação e experiência do que em qualquer outro campo da medicina. (6)

Arte porque utiliza um sistema muito apurado e requintado em busca da verdade, uma arte objetiva e coerente que coloca o analista frente à compreensão precisa e lógica, aplicando uma formulação de conceitos que em outras áreas não teriam a mesma importância na investigação lógica do resultado. (6) 
Utiliza-se a tecnologia de imagem moderna, como tomografia computadorizada, ressonância magnética e digitalização 3D, para detectar e documentar provas forenses, aperfeiçoar a autópsia clássica independentemente do observador, seja ele vivo ou morto. A virtópsia é uma ferramenta de identificação e exame rápido em desastres de grande escala. (7)

Apesar de esses procedimentos não fornecerem uma imagem real do interior do corpo, eles permitem reconstituir a região anatômica e obter informações sobre vários aspectos como densidade, calibrações, possíveis trajetórias e condições fotográficas que serão armazenadas em um protocolo padrão, chamado DICOM (Digital Imaging Communications in Medicine). (7)

O protocolo DICOM tem como finalidade padronizar as imagens diagnosticadas, possibilitando que essas imagens e informações associadas sejam trocadas entre equipamentos de imagem, computadores e hospitais, estabelecendo uma linguagem universal entre equipamentos de marcas diferentes, que no geral não são compatíveis. (7)

A virtópsia vem se mostrando superior em relação aos procedimentos tradicionais de necropsia, mantém os mesmos métodos de documentação e descrição utilizados nos casos tradicionais de necropsia. A necropsia tradicional se baseia em métodos de cortes ou até mesmo mutilação para alguns familiares; a dificuldade em realizá-la tem se tornado maior. Na grande maioria dos países, as necropsias só são feitas com a permissão da família. (7)

Um exemplo é a religião judaica, que determina um apreço pelo corpo e a alma, colocando em dúvida se o falecido gostaria que mutilasse a imagem a qual foi criado. A fim de buscar uma alternativas para esse tipo de situações, algumas opções de diagnóstico foram desenvolvidas. Esse novo método se baseia em analisar internamente o corpo sem a necessidade de abri-lo, utilizando tomografia computadorizada (TC), ressonância magnética (RM) e possibilitando a reconstrução em 3D do cadáver analisado. (7)

Na Medicina Legal, as técnicas mais utilizadas são a TC, a RM e a digitalização em 3D. A TC oferece uma ilustração geral do corpo e suas patologias. Diferente de raios $X$ convencionais, a TC proporciona uma visão tridimensional do órgão e dos tecidos. (8)

Do lado contrário à fonte, há detectores que convertem a radiação em um sinal elétrico, formando uma imagem digital. Essa imagem digital obtida pode ser manipulada e registrada de diferentes formas, mostrando as fatias do crânio e seu brilho refletido pelos raios X. (8) A TC ainda tem a habilidade restrita em distinguir a massa cinzenta e a massa branca.

A RM produz imagens em múltiplos planos, permitindo detalhes sobre regiões e órgãos exclusivos, tendo a capacidade de diferenciar estruturas como ossos e músculos. (8) Na RM, o fundamento se deve à maior quantidade de núcleos de hidrogênio $(H)$ nos tecidos moles, cujo alinhamento e desalinhamento desses núcleos são induzidos por um campo magnético e, consequentemente, o processamento da imagem. A RM é baseada em três etapas: alinhamento, estímulo e detecção de radiofrequência. 0 alinhamento se refere à propriedade magnética de núcleos de alguns átomos, que tendem a se orientar paralelamente a um campo magnético (como uma bússola em relação ao campo magnético da terra). Assim, para que esses átomos sejam orientados em certa direção, é necessário um campo magnético intenso - habitualmente cerca de 1,5 Teslas ( 30 mil vezes mais intenso que o campo magnético da Terra). (9)

A etapa seguinte é a excitação. Sabe-se que cada núcleo de hidrogênio "vibra" em determinada frequência proporcional ao campo magnético em que está localizado. Assim, em 1,5 T, o hidrogênio tem frequência de $63,8 \mathrm{MHz}$. O aparelho emite então uma onda eletromagnética nessa mesma frequência. (9)

Existe uma transferência de energia da onda emitida pelo equipamento para os átomos de hidrogênio. A terceira etapa é a detecção de radiofrequência. Quando os núcleos de hidrogênio receberam a energia, tornaram-se instáveis. Ao retornar ao estado habitual, eles emitem ondas eletromagnéticas na mesma frequência $(63,8 \mathrm{MHz}$ - faixa de ondas de rádio). (9)

Então, o equipamento detecta essas ondas e determina a posição no espaço e a intensidade da energia. Essa intensidade é mostrada como "brilho" na imagem, sendo utilizada a nomenclatura intensidade de sinal. (9) 
As técnicas chamadas API (Application Programming Interface) são conjuntos de procedimentos aplicados nas imagens digitais com a finalidade de um processo científico. (9)

A renderização digital das imagens em 3D são aplicadas em diversos campos da ciência forense. Esta técnica produz resultados espetaculares nos procedimentos necroscópicos; é um artifício tecnológico capaz de fornecer informações precisas sobre lesões, executar recriações animadas dos eventos e da cena do crime, gerando elementos extraordinariamente úteis ao contrastar várias hipóteses em um caso. (9)

Para navegar através de modelos em 3D, utilizamos Flashpoint 5000, Image Guided Technologies, Boulder e Medico 3D, conhecidos como digitalizadores ópticos que consistem em três câmaras alienadas capazes de captar pequenos sinais para a reconstrução anatômica em 3D. Técnicas de processo de imagens ou processos gráficos são capazes de modificar algumas características das imagens buscando melhorar a qualidade, detectar detalhes visíveis, invisíveis ou ocultos. (9)

Esses processos podem incluir ampliação, filtros, detecção de borda, subtração de planos de fundo e imagens, reconstrução (2D, 3D), interação de pixel (divisão, multiplicação, adição, subtração), manipulação matemática de pixels (por meio de operações ou funções aritméticas), segmentação e outros processos gráficos. (9)

Técnicas de análise das imagens são operações de natureza mensurável realizadas em uma imagem e os cálculos prevalecem como elementos principais dos dados analisados. Pela análise da imagem, obtemos dados métricos, formas, perímetro, número de objetos, densidade óptica, cor, distância entre objetos, ângulos e trajetos. As técnicas utilizadas podem incluir morfometria, densitometria, reconstruções tridimensionais, colorimétrica e outros recursos tecnológicos. (10)

Os avanços tecnológicos contribuíram com elementos inovadores nos estudos da traumatologia forense, principalmente na análise minuciosa de lesões, mecanismos traumáticos, tipos de instrumentos utilizados e ações vulnerantes. (11) $\mathrm{Na}$ tanatologia forense, a tecnologia tem contribuído nos exames pericias dos desastres em massa por meio da espectroscopia por RM e dos procedimentos densitométricos em detritos ósseos. (11)

$\mathrm{Na}$ antropologia forense, a utilização da morfometria e densitometria por TC revelam parâmetros antropométricos. A densitometria fornece dados detalhados da mineralização óssea para cálculo da provável data de morte. (11)

A TC multi-slice (TCMS) tem grande aplicação na abordagem antropológica para determinação da idade, podendo-se realizar a mensuração óssea em diferentes ângulos, propiciada pela reconstrução em 3D. (11)

Achados típicos de trauma na radiologia clínica são igualmente bem visualizados na imagem pós-morte. O aumento da pressão intracraniana, resultado de trauma ou isquemia, geralmente se manifesta na autópsia como hérnia transtentorial do lobo temporal ou hérnia do cerebelo no forame magno, com impressões na base do cerebelo correspondendo ao forame magno. (11)

Se houver um achado patológico grave no cérebro responsável pelo aumento da pressão intracraniana, a imagem pós-morte permite uma visualização detalhada. A radiologia é extremamente útil nos estágios avançados de putrefação que inviabilizam a investigação de uma autópsia, principalmente das estruturas remanescentes do cérebro quando o crânio é aberto. Nesses casos, a ressonância magnética pós-morte fornece uma visão anatômica adequada do cérebro in situ e permite a exclusão de alterações patológicas graves no cérebro. (11)

Estudos recentes investigaram a sensibilidade e o significado das imagens de RM pós-morte para alterações cerebrais discretas. Os exames iniciais de imagem em 3-T de RM dos corpos indicam que a falta de sensibilidade suficiente para lesões cerebrais menores que $5 \mathrm{~mm}$ em sistemas de 1,5-T pode ser superada pelo aumento da força do campo, com uma possível matriz de imagem até 1024. Os estudos de imagem por tensor de difusão prometem superar as atuais limitações da imagem transversal na visualização de pequenas lesões cerebrais em regiões de importância vital. (11)

A maioria das mortes naturais é causada por insuficiência cardíaca. Doenças cardíacas crônicas (por exemplo, cardiomiopatias) ou situações isquêmicas agudas. Além disso, o coração é frequentemente alvo de lesões tanto em suicídios 
quanto em homicídios. As lesões no coração geralmente se manifestam na imagem pós-morte como tamponamento pericárdico. (11)

Em contraste com as técnicas tradicionais de autópsia, a TC post mortem permite a visualização 3D detalhada das estruturas embolizadas, com quantificação do ar embolizado. Nos exames radiológicos dos pulmões, o pneumotórax e o edema pulmonar são facilmente detectados. (12)

As alterações pulmonares nas imagens axiais post mortem podem ser mascaradas por uma sobreposição de sedimentação sanguínea diretamente correlacionada ao tempo de morte (livores internos). (12)

Em casos típicos de afogamento, os pulmões se manifestam com "enfisema aquoso" e toque retroesternal dos lobos superiores. Em combinação com o fluido de afogamento ingerido ativamente no trato gastrointestinal, esse achado indica um processo de afogamento consciente (vital). (12)

Pela TCMS é possível diagnosticar com certeza um caso de hemorragia extrapleural no denominado sinal do "ápice em chapéu" que pode indicar ruptura de aorta ou hemorragia extrapleural. (12)

As inovações na patologia forense são especialmente sobre as novas técnicas utilizadas no estudo das lesões e causas de morte. A radiologia forense identifica hematomas ocultos, auxilia o estudo do impacto, das trajetórias de lesões causadas por armas de fogo ou armas brancas, e tem sido muito útil para esclarecer causas de morte. Além disso, as medidas morfométricas das lesões são extremamente precisas, permitindo documentação completa do caso e o reexame se necessário. (12)

\section{RESULTADOS}

Na última década, a ciência forense se aprimorou, influenciada por inovações e avanços tecnológicos. A radiologia e a informática compartilham suas tecnologias de imagem moderna como tomografia computadorizada, ressonância magnética e digitalização em 3D para detectar e documentar provas forenses, complementando e aperfeiçoando a autópsia clássica e os processos pericias investigativos. (13)

A vantagem da virtópsia são as reconstruções de TC e RM nos planos sagital, coronal e 3D, que podem indicar com precisão a localização de instrumentos e projéteis que lesionaram o corpo e causaram a morte sem danificar o cadáver. São métodos não invasivos e não apresentam perigo em relação a infecções causadas por sangue ou outros fluidos, como pode acontecer na autópsia convencional. A virtópsia vem sendo aceita, também, por questões religiosas e crenças. (13)

Como desvantagens, pode-se pontuar o alto custo dos exames e a não diferenciação das feridas in vivo em relação às feridas de post mortem, nem a coloração das lesões. Mesmo assim, acredita-se que esses métodos sejam cada vez mais utilizados como complementares à autópsia convencional. (13)

Em 2013, o Instituto Médico-Legal do Estado de São Paulo iniciou uma nova etapa, acompanhando os grandes centros periciais mundiais, com a implantação do método de Tomografia Computadorizada Multidetectores. (13)

o Centro Austríaco de Inovação e Tecnologia Médica desenvolveu o mais novo aparelho de autópsia virtual, o Virtobot, que é um sistema robótico que executa uma variedade de tarefas em conjunto com o escâner TC, permitindo a documentação de superfície 3D automatizada e de alta resolução, bem como amostragem de tecido post mortem guiada por TC. (13)

\section{CONCLUSÃO}

Notamos que a Virtópsia é um grande avanço no campo de investigação da causa da morte, tem suas vantagens sobre a autópsia tradicional, bem como suas desvantagens. (14)

A virtópsia pode ser feita em cadáveres altamente infectados ou com exposição radioativa. A dissecção do corpo é mínima, proporcionando uma abordagem mais humanitária. É preferido pelos membros da família devido à sua natureza não invasiva. Economiza tempo e dados, que podem ser armazenados indefinidamente. As opiniões são mais independentes do observador e menos subjetivas. (14)

Pode ser usado para complementar autópsias padrão e aumentar a qualidade delas. Permite análises adicionais no mesmo corpo por outros patologistas forenses, ou seja, se as alegações surgirem no futuro, segundas ou terceiras opiniões poderão ser buscadas, mesmo anos depois. (15)

As ferramentas de visualização aumentam a qualidade e a eficiência dos métodos forenses. 
Infecções e riscos à saúde de especialistas forenses podem ser reduzidos. Ao contrário de uma autópsia tradicional, uma virtópsia não destrói os tecidos humanos. (15)

Uma das grandes desvantagens é o banco de dados, que tem informações insuficientes para uma boa comparação entre a virtópsia e a autópsia convencional, além de não conseguir diferenciar feridas ante mortem das de post mortem, coloração das lesões e pode deixar passar despercebido lesões teciduais de pequenos portes. (15)

Apesar de ser uma técnica inovadora na medicina legal, a virtópsia não irá substituir a autópsia convencional, ela é mais um instrumento a ser usado em casos de dúvidas de diagnóstico ou até mesmo em casos antigos onde não se encontra mais um corpo. (15)

A TC é a ferramenta de escolha para documentação e análise 2D e 3D de sistemas de fraturas, coleções patológicas de gases (embolia aérea, enfisema subcutâneo após trauma, trauma hiperbárico, efeitos da decomposição) e lesão tecidual grave. (15) Os tempos de digitalização da TC são curtos (a documentação de todo o corpo leva de 5 a 10 minutos), dependendo da espessura da seção e do volume a serem cobertos. Técnicas de pósprocessamento, como realidade virtual e digitalização em 3D, podem fornecer fortes evidências visuais para uso em procedimentos nos tribunais. (15)

A ressonância magnética teve claramente um impacto maior na demonstração de lesão de tecidos moles, traumatismo neurológico, bem como trauma não neurológico e condições não traumáticas. No entanto, as diferenças nas características morfológicas e na intensidade do sinal observadas nas imagens de RM ante mortem versus post mortem ainda não foram estudadas sistematicamente. (15) O método de documentação dos achados forenses influencia nas melhorias qualitativas da investigação patológica forense, uma vez que os dados armazenados digitalmente podem ser recuperados a qualquer momento para fornecer informações topográficas e anatômico-clínicas novas e intactas. (15)

Maiores graus de controle de qualidade e supervisão dos especialistas se tornam possíveis, assim como a transmissão de imagens e a consulta forense em "telemedicina". Os métodos dimensionais 3D de reconstrução são superiores às técnicas descritivas e fotográficas mais antigas na demonstração abrangente de descobertas para leigos em um ambiente de tribunal. (15)

Com a expansão da aquisição de dados, os dados e as informações resultantes podem ser utilizados como base epidemiológica para avaliar a morbimortalidade na população em geral, auxiliando no planejamento de novos projetos de pesquisa. A autópsia virtual fornece um meio alternativo de obter dados post mortem relevantes para futuras pesquisas. (15)

Os desenvolvedores da autópsia virtual não apresentam esse procedimento como um substituto para a autópsia tradicional, mas como um exame complementar ou uma ferramenta a ser usada nos casos em que a dissecção do corpo não é viável ou cuja evidência forense é particularmente difícil de visualizar. (15)

\section{REFERÊNCIAS BIBLIOGRÁFICAS}

1. García-Espinoza B. Generalidades sobre las autopsias. Elect J Autop. 2008; 6(1): p4-18.

2. Novo BN, Almeida BR. Medicina legal e perícia médica. Rev Jus Nav. [Online]; 2019 [ Acesso em: 20 jul. 2019.] Disponível em: https://jus.com.br/artigos/72440/medicina-legal-epericia-medica.

3. Muñoz DR, Gianvecchio V, Miziara I. Especialidades Médicas - Medicina legal e perícias Médicas. Rev Méd. 2012; 91(ed. esp.): p45-48.

4. Burto JL, Underwood, J. Clinical, educational, and epidemiological value of autopsy. Lancet. 2007; 369: p1471-1480.

5. Burton EC, Mossa-Basha M. To image or to autopsy? Ann Intern Med. 2012; 156(2): 158-159.

6. Thali MJ, Jackowski C, Oesterhelweg L, Ross SG, Dirnhofer R. Virtopsy - The swiss virtual autopsy approach. Leg Med. 2007; 9(2): p100-104.

7. França GV. Medicina legal. 7ed. Rio de Janeiro: Guanabara Koogan; 2004.

8. Chevallier C, Doenz F, Vaucher P, Palmiere $C$, Dominguez A, Binaghi $S$, et al. Postmortem computed tomography angiography vs. conventional autopsy: advantages and inconveniences of each method. Int J Leg Med. 2013; 127: p981-989.

9. Thali MJ, Yen K, Schweitzer W, Vock P, Boesch 
C, Ozdoba C, et al. Virtopsy, a new imaging horizon in forensic pathology: virtual autopsy by postmortem multislice computed tomography (MSCT) and magnetic resonance imaging (MRI) - a feasibility study. J For Sci. 2003; 48: p386-403.

10. Thali MJ, Kneubuehl B, Vock P, Allmen GV, Dirnhofer R. High-speed documented experimental gunshot to a skullbrain model and radiologic virtual autopsy. Am J Forensic Med Pathol. 2002; 23(3): p223-228.

11 Dedouit, F. Telmon N, Guilbeau-Frugier C, Gainza $D$, Otal P, Joffre F, et al. Virtual autopsy and forensic identification-practical application: a report of one case. J For Sci. 2007: 52(4): p960-964.

12. Bolliger SA Thali MJ, Aghayev E, Jackowski C, Vock P, Dirnhofer R, Christe A. Postmortem noninvasive virtual autopsy: extrapleural hemorrhage after blunt thoracic trauma. Am J For Med Path. 2007; 28(1): p44-47.

13. Bolliger SA, Thali MJ, Ross S, Buck U, Naether S, Vock P. Virtual autopsy using imaging: bridging radiologic and forensic sciences. A review of the Virtopsy and similar projects. Eur Rad. 2008 (Epub 2007); 18(2): p273-282, 2008.

14 Thali MJ, Yen K, Vock P, Ozdoba C, Kneubuehl $B P$, Sonnenschein $M$, Dirnhofer R. Image-guided virtual autopsy findings of gunshot victims performed with multi-slice computed tomography (MSCT) and magnetic resonance imaging (MRI) and subsequent correlation between radiology and autopsy findings. For Sci Int. 2003; 138: p8-16.

15. Dirnhofer R, Jackowski C, Vock P, Potter K, Thali MJ. Virtopsy: minimally invasive, imaging-guided virtual autopsy. RadioGraphics. 2006; 26: p13051333. 


\title{
GABMLPM
}

\section{Associação Brasileira de Medicina Legal \\ e Perícias Médicas}

\author{
DIRETORIA EXECUTIVA 2019-2022 \\ Presidente \\ Dr. Ivan Dieb Miziara (SP) \\ Vice-Presidente \\ Dra . Rosa Amélia Andrade Dantas (SE) \\ 10 Secretário \\ Dr. Reginaldo Inojosa Carneiro Campello (PE) \\ 20 Secretário \\ Dr. Norberto Rauen (SC) \\ 1a Tesoureira \\ $D^{a}$. Daniele Muñoz Gianvecchio (SP) \\ 2o Tesoureiro \\ Dra. José Marques de Oliveira Neto (SE)
}

\section{CONSELHO FISCAL}

Dr. Luiz Carlos Leal Prestes Junior (RJ)

Dr. Francisco Miguel Roberto Moraes Silva (PR)

Dr. Maximiano Leite Barbosa Chaves Leite (CE)

Dr. João Anastácio Dias (GO)

Dra. Maria Luisa Duarte (AL)

Dra . Gabriela Graça Suares Pinto (RJ)
CONSELHO TÉCNICO CIENTÍFICO

Coordenador

Dr. José Jozefran Berto Freire

Membros

Dr. Victor Alexandre Percinio Gianvecchio

Dr. Alcindo Cerci Neto

Dra ${ }^{a}$. Viviam Paula Lucianelli Spina

Dr. Sami Abder Rahim Jbara El Jundi

Dr. Demercindo Brandão Neto

Dr. Samuel Teixeira Gomes Ferreira

Dr. Pedro Artur Lobato Baptista

\section{CONSELHO DE ENSINO, TITULAÇÃO E CERTIFICAÇÃO}

DEPARTAMENTO DE DEFESA PROFISSIONAL

\section{Coordenadora}

Dra . Daniele Muñoz Gianvecchio

\section{Membros}

$\mathrm{Dr}^{\mathrm{a}}$. Carmen Silvia Molleis Galego Miziara Dra ${ }^{a}$. Silvia Cléa Coutinho Ramos

Dra . Anellys Emília Lourenço da Costa Moreira

Dr. Luiz Carlos Leal Prestes Junior

Dr. Flaviano Biváqua de Araújo

Dr. Renato Evando Moreira Filho

Dr. Norberto Rauen

\section{Coordenadora}

Dra. Gabriela Graça Suares Pinto

\section{Membros}

$D^{a}$. Barbara Mary de Araújo Pereira Dr. Luiz Guilherme Cardoso Moll

Dra ${ }^{\text {a }}$ Marisa dos Santos Feiten Dra . Maria de Fátima FVM

$\mathrm{Dr}^{\mathrm{a}}$. Ana Carolina de Almeida Couto Dr. Marcus Barreto Conde Dr. Marcos Antônio Alvarez Dra. Maristela Gonçalves Olival Dr. Marcelo Elias Shempf Cattan Dr. Ricardo Campos Barcellos 